\title{
EDUCAÇÃO MATEMÁTICA E ESTUDOS (AUTO) BIOGRÁFICOS: UM CAMPO DE INVESTIGAÇÃO EM CONSTRUÇÃO
}

- ADAIR MENDES NACARATO

Universidade São Francisco

KÁTIA GABRIELA MOREIRA

Universidade São Francisco

IRIS APARECIDA CUSTÓDIO

Universidade São Francisco

RESUMO Esta é uma pesquisa de revisão sistemática que considera parte da produção nacional no campo (auto)biográfico em Educação Matemática. Ela tem como objetivo identificar o movimento de produção nacional dos educadores matemáticos, no que se refere às pesquisas que têm aproximações com os estudos (auto)biográficos. Para isso, utilizou-se o recorte temporal de 2010 a 2018 - o ano de 2010 por ser um marco nessa modalidade de pesquisa, com a publicação do trabalho de Souza (2010), que analisa a produção sobre narrativas de educadores matemáticos; e 2018, por ser o ano que antecede a realização desta pesquisa. Como fonte de dados, tomaram-se os Anais das edições do CIPA (cinco, no total), os Anais do GT19 da Anped e os periódicos qualificados em Educação e Educação Matemática. Os resultados revelam uma diversidade de modos de produção (com) e de entendimento sobre narrativas pelos educadores matemáticos. Apesar da ampla produção na área, cuidados éticos e teórico-metodológicos precisam ser levados em consideração nesta modalidade de investigação.

Palavras-chave: Educação Matemática. Narrativas (auto)biográficas. Pesquisa (com) narrativas.

\section{ABSTRACT MATHEMATICS EDUCATION AND (AUTO)BIOGRAPHICAL STUDIES: A FIELD OF RESEARCH UNDER CONSTRUCTION}

This is a systematic review research that systematizes part of the national production in the (auto)biographical field in mathematics 
education. It aims to identify the national production movement of mathematics educators with regard to research that has approximations to (auto)biographical studies. For this purpose, the period between 2010 and 2018 was used - the year 2010 being a milestone in this research modality with the publication of Souza's work (2010), which analyzes the production on narratives of mathematics educators; and 2018, for being the year preceding this research. As a data source, we have taken the Annals of the CIPA editions (five in total), Annals of Anped's GT19 and specialized periodicals in Education and Mathematics Education. The results show that there is a diversity of modes of production (with) and of understanding about narratives by mathematics educators. Despite the wide production in the area, ethical and theoretical-methodological care must be taken into account in this research modality.

Keywords: Mathematics Education. (auto)biographical narratives. research (with) narratives.

\section{RESUMEN LA EDUCACIÓN MATEMÁTICA Y ESTUDIOS (AUTO) BIOGRÁFICOS: UN CAMPO DE INVESTIGACIÓN EN CONSTRUCCIÓN}

Esta es una investigación de revisión sistemática que sistematiza parte de la producción nacional en el campo (auto)biográfico en la educación matemática. Tiene como objetivo identificar el movimiento de producción nacional de los educadores matemáticos en lo que se refiere a las investigaciones que tienen proximidad con los estudios (auto)biográficos. Para esto, se utilizó el recorte temporal de 2010 a 2018 - el año 2010 por ser un marco en esta modalidad de investigación con la publicación del trabajo de Souza (2010), que analiza la producción sobre narrativas de educadores matemáticos; y 2018, por ser el año que antecede a la realización de esta investigación. Como fuente de datos se tomaron los Anales de las ediciones del CIPA (cinco en total), Anales del GT19 de la Anped y periódicos calificados en Educación y Educación Matemática. Los resultados indican que hay una diversidad de modos de producción (con) y de entendimiento sobre narrativas por los educadores matemáticos. A pesar de la amplia producción en el área, es necesario tomar en consideración los cuidados éticos y teórico-metodológicos en esta modalidad de investigación.

Palabras clave: Educación Matemática. narrativas (auto)biográficas. investigación (con) narrativas. 


\section{O início da conversa}

Pesquisas na área de Educação, pautadas no método (auto)biográfico, vêm se difundindo no contexto brasileiro. Muitos são os trabalhos de dissertação e tese desenvolvidos nos programas de pós-graduação, bem como artigos publicados em periódicos e em anais de eventos. No caso da Educação Matemática, a situação não é diferente. Pode-se dizer que, na última década, essa temática vem se fazendo presente nas pesquisas de educadores matemáticos.

Um marco na produção em Educação Matemática foi o número temático publicado em 2010, decorrente do trabalho encomendado na 32.a Reunião Anped/2009, no GT19 Educação Matemática. Naquele ano, os participantes do GT elegeram a temática das narrativas como foco para o trabalho encomendado; a partir dos textos submetidos ao GT, o professor Elizeu Clementino de Souza elaborou uma sintese e discussão teórico-metodológica, e todos os textos foram publicados no dossiê "Narrativas autobiográficas e História Oral", da Ciências Humanas e Sociais em Revista (volume 32, julho/dezembro 2010), organizado por Elizeu Clementino de Souza e Adair Mendes Nacarato (coordenadora do GT19 naquela época). Em seu texto, Souza (2010) já destacava a polissemia que envolvia a temática e as duas abordagens que se faziam presentes na produção dos educadores matemáticos: pesquisa narrativa (ou com narrativas) e História Oral (HO). Nesse texto, ele faz uma síntese analítica dos trabalhos desenvolvidos. Desde então, um número significativo de estudos vem sendo produzido nesse campo de investigação, e dois dossiês ou números temáticos já foram publicados em periódicos nacionais: um deles, em 2013, "Seção Temática: Escritas, narrativas \& formação docente em Educação Matemática" - Revista de Educação PUC-Campinas, 2013, organizado por Adair Mendes Nacarato e Cármen Lú- cia Brancaglion Passos; o segundo, "Narrativas na pesquisa em Educação Matemática", foi um número temático do Boletim de Educação Matemática - Bolema (v. 28, n. 49, em 2014), organizado por Adair Mendes Nacarato, Cármen Lúcia Brancaglion Passos e Heloisa da Silva. No dossiê temático da Revista de Educação da PUC-Campinas, as organizadoras não elaboraram uma síntese analítica dos textos, diferentemente da edição temática do Bolema. Assim, no presente artigo, apenas os textos do primeiro dossiê comporão o corpus da pesquisa.

Além desses dossiês, destaca-se também o artigo de Nacarato, Oliveira e Fernandes (2017), no qual as autoras realizam uma sistematização das pesquisas presentes no "Mapeamento da pesquisa acadêmica brasileira sobre o professor que ensina Matemática: período 20012012" (FIORENTINI; PASSOS; LIMA, 2016), projeto de âmbito nacional, do qual fizeram parte como pesquisadoras. Esse mapeamento considerou as dissertações e as teses desenvolvidas no período. Em seu artigo, elas destacam dois focos temáticos identificados no mapeamento: "História da formação do professor que ensina Matemática" e "História do professor que ensina Matemática", visando identificar aproximações entre a metodologia da História Oral e o método (autobiográfico). As autoras concluíram: "a análise desses dois focos nos possibilitou identificar que a aproximação entre eles vai além da questão metodológica: as vozes do sujeito professor e o seu protagonismo na construção da história da Educação Matemática constituem o fulcro dessa proximidade" (NACARATO; OLIVEIRA; FERNANDES, 2017, p. 66).

Dois outros espaços vêm se fazendo profícuos para o compartilhamento de pesquisas com narrativas: os Congressos Internacionais de Pesquisa (Auto)Biográfica - CIPA - e as reuniões nacionais da Associação Nacional de 
Pós-Graduação e Pesquisa em Educação ANPED, no GT19 Educação Matemática. Desde a nossa inserção nesse campo de investigação, temos participado assiduamente das edições desses congressos e constatado a presença de pesquisas nessa temática por educadores matemáticos.

Diante da chamada para o "Dossiê Percursos narrativos em Educação Matemática", da Revista Brasileira de Pesquisa (Auto)Biográfica, fomos mobilizadas para a elaboração do presente trabalho, visando realizar uma sistematização da produção nacional nesse campo de inquérito, no período de 2010-2018.

O texto está organizado em quatro seções: 1) a apresentação dos procedimentos metodológicos, na qual definimos a modalidade de pesquisa, a justificativa do recorte temporal, os procedimentos para a seleção do corpus da pesquisa e o procedimento analítico; 2) um olhar para os trabalhos compartilhados no CIPA, com que buscamos identificar o movimento da produção dos educadores matemáticos; 3) os modos de produção (com) narrativa dos educadores matemáticos; e 4) uma síntese analítica dos resultados da investigação.

\section{Procedimentos metodológicos da pesquisa}

Esta é uma pesquisa de revisão sistemática, que se aproxima de um estado da arte ou do conhecimento. As pesquisas de revisão sistemática, segundo entendimento do Grupo de Estudos e Pesquisas sobre Formação de Professores (GEPFPM, 2018, p. 233), utilizam um “processo metódico e rigoroso de busca e seleção de fontes primárias, de coleta de dados/ informações, de análise/interpretação e de sistematização e produção de sínteses integradoras das evidências encontradas". Nessa modalidade de pesquisa, aquelas do tipo es- tado da arte ou do conhecimento - entendidas como sinônimos - são utilizadas

quando o pesquisador busca sistematizar os resultados (isto é, os conhecimentos) produzidos em um determinado campo de estudo ou temática de pesquisa, durante um período de tempo. Assim, ele faz, ao final, um balanço síntese do conhecimento produzido, evidenciando contribuições e questões ou temáticas em aberto e que demandam investigações. (GEPFPM, 2018, p. 241)

Nessa modalidade de investigação, há que se partir de uma questão norteadora, e, no nosso caso, nos norteamos pela seguinte questão: "O que se tem produzido de pesquisas (auto)biográficas no campo da Educação Matemática?" Assim, este trabalho tem como objetivo identificar o movimento de produção nacional dos educadores matemáticos, no que se refere às pesquisas que têm aproximações com os estudos (auto)biográficos.

0 recorte temporal por nós utilizado foi 2010-2018 porque, conforme explicitado na seção anterior, o ano de 2010 é por nós considerado um marco nessa modalidade de pesquisa, com o trabalho de Souza (2010), ao analisar a produção sobre narrativas de educadores matemáticos. E 2018 antecede a realização desta pesquisa.

Nessa modalidade de investigação, a delimitação do corpus de pesquisa é sempre um desafio. 0 trabalho de Nacarato, Oliveira e Fernandes (2017) analisou a produção brasileira de dissertações e teses, no período 2002-2012, tomando como ponto de partida um mapeamento nacional realizado por uma ampla equipe de investigadores (FIORENTINI; PASSOS; LIMA, 2016). Assim, poderíamos ter dado continuidade ao recorte temporal desse mapeamento; no entanto, avaliamos que tal pesquisa exigiria um grupo maior de pesquisadores; além disso, o início da busca dos textos para a composição do corpus de nossa pesquisa já sinalizou que 
contaríamos com um número significativo de trabalhos. Daí nossa opção por analisar: anais de dois eventos e sete periódicos, que consideramos ser referências em Educação e Educação Matemática e são avaliados pelo Qualis Capes. Os anais considerados foram: dos Congressos Internacionais de Pesquisa (Auto) Biográfica - CIPA; e das reuniões nacionais da Associação Nacional de Pós-Graduação e Pesquisa em Educação - a Anped -, mais particularmente do GT19 de Educação Matemática. Os periódicos considerados foram: Boletim de Educação Matemática (Bolema - Unesp/Rio Claro), Zetetiké (FE/Unicamp), Revista Eletrônica de Educação (Reveduc - UFSCar), Perspectivas em Educação Matemática (UFMS), Revista Educação PUC-Campinas; Revista Brasileira de Pesquisa (Auto)Biográfica (RBPAB); e Educar em Revista (UFPR). Tal escolha decorreu do fato de termos conhecimento de narrativas neles publicadas. A busca também foi realizada na plataforma do Scielo e identificamos um trabalho na Educar em Revista, que foi incorporado ao corpus da pesquisa. A partir desses critérios, temos certeza de que outros trabalhos ficaram ausentes da sistematização aqui apresentada.

Para a realização das buscas pelos trabalhos que comporiam o corpus de investigação, utilizamos os seguintes critérios:

- Anais dos Congressos Internacionais de Pesquisa (Auto)Biográfica - CIPA: utilizamos, inicialmente, a palavra "matemática" como descritor no título. Em seguida, nos detivemos em títulos que continham expressões como: "formação de professores", "escritas de si", "trajetórias de formação" e "narrativas de crianças ou de infância" e procedemos à sua leitura, buscando identificar a presença (ou não) do termo "matemática". Isso porque, muitas vezes, os autores reduzem o título do texto, em virtude das normas de publicação impostas pela organização do evento. Após a identificação dos trabalhos, passamos à leitura e à elaboração de suas sínteses, destacando: o objeto de investigação; a modalidade de trabalho (comunicação, pôster, sessão coordenada de grupos de pesquisa, sessão conversa ou simpósio temático); as fontes utilizadas; a identificação como pesquisa ou relato de experiência etc. Porque os Anais do Cipa passaram a ser on-line somente em 2016 (VII CIPA), para o levantamento dos trabalhos do IV, V e VI CIPAs, lançamos mãos dos CD-ROM, o que demandou longo tempo para a leitura de cada texto que pressupúnhamos tivesse relação com a temática do nosso trabalho. Como nem todos os títulos contêm o termo "matemática", é possível que tenhamos deixado alguns textos fora do corpus de análise. 0 Quadro 4, do Apêndice 2 contém a relação dos trabalhos identificados nos Anais do CIPA.

- Anais das reuniões do GT19 da Anped: consultamos a programação de todas as reuniões, no período delimitado para a pesquisa, e, a partir dos títulos e dos resumos disponíveis, selecionamos os que comporiam este corpus. Vale destacar que as reuniões nacionais da Anped eram anuais até 2012; depois passaram a ser bianuais. No ano de 2010, não foram identificados estudos com narrativas. A consulta foi realizada com facilidade, visto que todos os anais estão on-line no portal da Anped.

- Periódicos: inicialmente delimitamos quais iriamos consultar. Decidimos por aqueles que têm representatividade no cenário da Educação e da Educação Matemática e que sabíamos, de antemão, que haviam publicado textos sobre narrativas. Todos os periódicos estão on-line; no entanto, o Bolema passou para o portal Scielo em 2014, e tivemos dificuldades em localizar os números anteriores a essa data, exigindo que recorrêssemos ao site do Redalyc; e a publicação on-line de Perspectivas em Educação Matemática é posterior

1 Disponivel em: $<$ https: / / www.redalyc.org>. Acesso em: 31 jan. 2019. 
a 2014. Dessa forma, algum trabalho pode ter ficado de fora do nosso corpus de investigação, mesmo considerando essas fontes. $\mathrm{Na}$ plataforma Scielo, utilizamos a palavra "narrativas" e, no montante de publicações, localizamos, em Educar em Revista, mais um texto de Educação Matemática. Também buscamos trabalhos no Boletim Gepem/UFRJ, mas nada identificamos no período considerado para a pesquisa.

O Quadro 1 contém o total de trabalhos localizados (127 no total).

Quadro 1 - Total de trabalhos que compõem o corpus da pesquisa

\begin{tabular}{|c|c|c|}
\hline Fonte & Evento ou Periódico e local & Total de trabalhos \\
\hline \multirow{6}{*}{ Anais CIPA } & 2010 - IV CIPA - USP & $\begin{array}{l}14+1 \text { sessão coordenada de } \\
\text { grupos de pesquisa }\end{array}$ \\
\hline & 2012 -V CIPA - PUCRS & 11 \\
\hline & 2014 - VI CIPA - UERJ & 19 \\
\hline & 2016 - VII CIPA - UFMT & $21+1$ simpósio temático \\
\hline & 2018 - VIII CIPA - Unicid/SP & 25 + 1 seminário temático \\
\hline & Total & 93 \\
\hline \multirow{5}{*}{$\begin{array}{l}\text { Anais Anped - } \\
\text { GT19 }\end{array}$} & 2011 - Porto de Galinhas & 1 \\
\hline & 2013 - Goiânia & 1 \\
\hline & 2015 - Florianópolis & 1 \\
\hline & 2017 - São Luís/MA & 1 \\
\hline & Total & 4 \\
\hline \multirow{8}{*}{ Periódicos } & Bolema & 7 \\
\hline & Educação PUC Campinas & 7 \\
\hline & Zetetiké & 7 \\
\hline & Perspectivas em Educação Matemática & 5 \\
\hline & Reveduc & 2 \\
\hline & $R B P A B$ & 1 \\
\hline & Educar em Revista & 1 \\
\hline & Total & 30 \\
\hline
\end{tabular}

Fonte: Organização das autoras.

Constituído o corpus dessa investigação, o próximo desafio foi a decisão pelo processo analítico. Considerando o espaço delimitado para o presente artigo, tomamos a seguinte decisão: para os Anais do CIPA, após a leitura de todos os textos, produzimos algumas sínteses - porém não as inserimos aqui - que nos ajudaram na análise do movimento de produção dos educadores matemáticos. Além disso, embora os textos apresentados no CIPA envolvam tanto pesquisa quanto relato de experiência, nosso foco é nas investigações. Sabemos que a exigência para a submissão, no caso do GT19 da Anped e dos periódicos, é de que sejam pesquisas concluídas. Assim, busca- 
mos analisar os modos de produção (com) narrativa dos educadores matemáticos.

\section{Um olhar para os trabalhos compartilhados no CIPA}

Identificamos seis modos de produção de dados para os trabalhos apresentados nas edi- ções do CIPA: narrativa de formação; história de vida; depoimento ou escrita de alunos; História da educação matemática; trabalho teórico (de sistematização ou discussão teóricometodológica); e biografia. 0 Quadro 2 traz o total de trabalhos em cada uma dessas modalidades. $^{2}$

Quadro 2 - Distribuição dos trabalhos por edição modalidade de uso de narrativas

\begin{tabular}{|l|c|c|c|c|c|c|}
\hline & $\begin{array}{c}\text { Narrativa } \\
\text { de } \\
\text { formação }\end{array}$ & $\begin{array}{c}\text { História } \\
\text { de } \\
\text { vida }\end{array}$ & $\begin{array}{c}\text { Depoimento } \\
\text { ou escrita dos } \\
\text { alunos }\end{array}$ & $\begin{array}{c}\text { História da } \\
\text { Educação } \\
\text { Matemática }\end{array}$ & $\begin{array}{c}\text { Trabalho } \\
\text { teórico }\end{array}$ & Biografia \\
\hline CIPA 2010 & 2 & 7 & 1 & 2 & 1 & 1 \\
\hline CIPA 2012 & 7 & 2 & 2 & 0 & 0 & 0 \\
\hline CIPA 2014 & 10 & 6 & 0 & 1 & 2 & 0 \\
\hline CIPA 2016 & 10 & 6 & 3 & 0 & 1 & 0 \\
\hline CIPA 2018 & 4 & 2 & 0 & 0 & 3 & 2 \\
\hline
\end{tabular}

Fonte: Organização das autoras.

Na modalidade Narrativa de formação, inserimos todos os estudos que utilizaram dispositivos de produção de dados, tais como registros ou diários reflexivos sobre a formação, narrativas sobre o processo vivenciado na formação inicial ou continuada e os memoriais de formação. Essa foi a modalidade mais presente nas cinco edições analisadas (33 trabalhos). Na formação inicial - Pedagogia ou Licenciatura em Matemática -, essas narrativas são produzidas em disciplinas do curso, como: Fundamentos e Metodologia do Ensino de Matemática ou título similar, no curso de Pedagogia; Conteúdo, Metodologia e Prática de Ensino de Matemática ou Fundamentos da Matemática Elementar, na Licenciatura em Matemática. Nos cursos de Licenciatura em Matemática, não identificamos estudos que abordem as narrativas de formação em disciplinas que não sejam voltadas à educação básica, ou seja, nas chamadas disciplinas específicas da matemática.
Na formação continuada, as narrativas foram geradas em programas como o Observatório da Educação (Obeduc) ou o Programa Institucional de Bolsa de Iniciação à Docência (Pibid), ou em projetos/grupos de estudos e pesquisas; alguns desses grupos são constituídos por estudantes da graduação e professores em exercício e, nesse caso, as narrativas foram tomadas como práticas de formação.

Algumas narrativas nos permitiram inferir que tenham sido desenvolvidas (por meio de entrevistas ou escritas pelo próprio sujeito) como fonte de dados para o pesquisador - por exemplo, para analisar o que, na ótica dos alunos, seria um bom professor. Há trabalhos que usam narrativas sob a perspectiva da $\mathrm{HO}$; ou, também, sobre a própria prática do professor

2 Vale destacar que, até à data da produção deste artigo, os Anais do CIPA 2018 não tinham sido publicados. Enviamos e-mails a todos os participantes (num total de 22), mas não obtivemos retorno de 11 deles. 
-pesquisador. Essa última modalidade pode se constituir em prática de formação que potencializa o desenvolvimento profissional do professor.

$\mathrm{Na}$ maioria dos textos não foi possível identificar qual teria sido o tratamento dado no contexto de sua produção: se houve compartilhamento entre os pares ou devolutiva para os depoentes - um compromisso ético do pesquisador narrativo. Muitos trabalhos não discutem a concepção teórica de narrativa (em suas múltiplas denominações) que norteou a investigação. Evidentemente, não há como negar que o limite de páginas estabelecido pelo evento para a submissão do texto pode impedir descrições mais detalhadas no texto.

A modalidade História de vida foi considerada para a análise quando a pesquisa abordou histórias de vida de professores e/ou formadores de professores, produzidas pelo pesquisador por meio de escuta (entrevistas narrativas ou outra metodologia que utilize a escuta da história do sujeito, que, por sua vez, faz seu relato a partir de temas direcionados pelo pesquisador ou de forma aberta). Posteriormente, tais histórias são textualizadas pelos pesquisadores, ou seja, são transcritas sem as marcas de oralidade ou a textualização, buscando construir uma narrativa de alguma forma cronológica; depois disso, elas podem ou não ser processadas como uma abordagem que possibilita aos participantes da pesquisa tomar consciência de sua trajetória de vida pessoal e/ou profissional por meio da devolutiva, visto que alguns pesquisadores se apropriam das histórias dos sujeitos como fontes de dados para a investigação. Mas não fica explícito se eles se comprometem com a necessária devolutiva dessa história aos sujeitos. Identificamos também trabalhos em que o pesquisador analisa sua própria história de vida.
Na modalidade Depoimento ou escrita de alunos, acolhemos todos os textos orais ou escritos produzidos por alunos nos diferentes níveis de ensino. Dentre eles, encontramos: escritas de carta por alunos dos anos iniciais; narrativas de estudantes da Educação de Jovens e Adultos; narrativas de estudantes dos anos iniciais nas aulas de matemática; narrativas de estudantes dos anos finais do ensino fundamental nas aulas de matemática; entrevistas narrativas com estudantes do ensino médio profissionalizante; e entrevistas narrativas com estudantes universitários. Todas as entrevistas também foram transcritas pelos pesquisadores.

Alguns trabalhos utilizam-se das narrativas como fonte de produção de dados para contextos de História da Educação Matemática. Nesse caso, os pesquisadores analisam contextos ou obras específicas, tais como escolas radiofônicas do Estado do Rio Grande do Norte; a vida e a obra de Guilherme Maurício Souza Marcos de La Penha (Pará); produção de materiais pedagógicos de Iniciação Matemática, na década de 1970; e a trajetória de João Antonio Coqueiro (Maranhão).

Denominamos como Trabalho teórico os textos que discutem metodologias de pesquisa ou pesquisas de mapeamento/sistematização envolvendo o estudo com/sobre narrativas como modo de compreender as experiências (o vivido) no campo da Educação Matemática. Alguns analisam: produções de educação matemática no CIPA, a partir dos aspectos teóricos e metodológicos; a própria produção do grupo de pesquisa ou obras específicas de pesquisa (obras de González Rey e Michael Connelly e Dean Clandinin); aspectos teóricos e metodológicos para a elaboração de pesquisa narrativa; anais de eventos e periódicos que contêm textos sobre formação de professores na abordagem com narrativas; e aproximações das narrativas com a História Oral. 
Finalmente, caracterizamos dois trabalhos na modalidade Biografia, em pesquisas cujos objetivos são: construir a trajetória da Professora Beatriz D'Ambrosio, a partir do mapeamento existente sobre a produção dessa educadora matemática; e compreender, a partir do entrecruzamento entre História Oral e biografia, como a professora Lourdes de la Rosa Onuchic se constituiu como educadora matemática.

Além dos trabalhos que constam dos Anais, há também os capítulos de livros publicados em cada uma das edições do CIPA. Os autores dos capítulos, geralmente, são os convidados para as sessões especiais, como as de grupos de pesquisa ou de simpósios temáticos.

No IV CIPA, em 2010, houve a Sessão coordenada de grupos de pesquisa: História Oral e Educação Matemática, que contou com os debatedores: Antonio Vicente M. Garnica Unesp Rio Claro; Adair Mendes Nacarato - USF; e Cármen Lúcia B. Passos - UFSCar. Cada pesquisador apresentou o movimento de seu grupo de pesquisa. Em 2016, no VII CIPA, ocorreu o Simpósio Temático "Narrativas e Educação Matemática", com a participação de Cármen Lúcia Brancaglion Passos - UFSCar, Adair Mendes Nacarato - USF e Heloisa da Silva - UNESP. Seu objetivo foi promover a apresentação, o debate e a interlocução de pesquisas que trabalham com as narrativas e as memórias em processos formativos formais de professores que ensinam matemática. Em 2018, houve outro simpósio temático: "Mobilidade e incertezas emergentes nas narrativas em Educação Matemática", contando com Celi Espasandin Lopes - Unicid/Unicsul, Maria Auxiliadora Bueno Andrade Megid - PUC-Campinas e Adair Mendes Nacarato - USF, que deu continuidade às discussões sobre as narrativas no campo da Educação Matemática, já ocorridas em edições anteriores do CIPA.

\section{Os modos de produção (com)}

\section{narrativa dos educadores}

\section{matemáticos}

Nesta seção, procedemos à análise dos artigos publicados pelo GT19 da Anped, em quatro de suas edições, com um trabalho em cada uma delas, e dos artigos publicados em periódicos, considerados para o corpus da pesquisa. Após a leitura detalhada de cada um dos 32 textos, buscamos identificar os modos de produção das pesquisas com narrativas pelos educadores matemáticos. 0 Quadro 3 do Apêndice 1 contém as referências dos trabalhos que compõem essa parte do corpus da pesquisa.

Identificamos cinco eixos para análise: uso de memoriais de formação; textos de escritas de si; narrativas de aulas ou de práticas; narrativas resultantes de entrevistas ou de autoria dos próprios sujeitos da pesquisa; e textos de sistematização ou teóricos. Evidentemente, essa organização é uma interpretação nossa; outras são possiveis.

Os memoriais de formação foram utilizados em três estudos: Silva (2011), Martins e Rocha (2013) - ambos apresentados no GT19 da Anped; e Rosa e Baraldi (2015), publicado no Bolema. Silva (2011) os utilizou, juntamente com questionário, entrevistas, observação e diário de campo, num curso de educação a distância, pela Universidade Aberta do Brasil. A autora realizou uma pesquisa narrativa com alunos-professores que exerciam a docência em matemática e buscou identificar, nos dossiês de três professores (organizados a partir das fontes de dados utilizados), os saberes relativos à prática docente e à formação superior, e os sentidos que os sujeitos dão à formação que recebem. Todo o material da pesquisa foi elaborado em plataforma on-line.

Martins e Rocha (2013) usaram os memoriais de formação produzidos por três licenciandos, com o objetivo de encontrar indícios 
de constituição de identidade docente de licenciandos em matemática.

Rosa e Baraldi (2015) utilizaram os memoriais no curso Braille on-line - Módulo Básico, oferecido pela Universidade Federal Fluminense (UFF). $O$ artigo apoia-se na pesquisa de mestrado da primeira autora, com foco na educação inclusiva, e toma para a análise quatro dentre todos os dez memoriais produzidos num blog criado para o curso.

O que podemos dizer dessas três produções: todas foram realizadas em contextos de curso, o que já pode indicar uma característica desse tipo de fonte de dados. As autoras assumem abordagens teóricas sobre os memoriais, considerando-os um tipo de narrativa (auto) biográfica. Tanto Martins e Rocha (2013) quanto Rosa e Baraldi (2015) tomam como referências os trabalhos de Maria da Conceição Passeggi e do grupo Gepec, coordenado por Guilherme do Val Toledo Prado. Elas destacam a importância do memorial para a reflexão sobre fatos vividos pelos sujeitos e para as reflexões geradas em relação a eles. No entanto, em nenhum dos trabalhos aparece como foi feita, e se foi, a mediação biográfica por parte do pesquisador, tal como defende Passeggi (2006; 2007), autora tomada como referência. Para essa autora, o conceito de mediação biográfica é inspirado nos estudos vigotskianos sobre a lei geral no desenvolvimento das funções psíquicas superiores por meio de microtransformações ao longo do tempo. Elas ocorrem em movimento duplo, na interação entre pessoas (interpsicológico) e na apropriação interna (intrapsicológico). Assim, o objetivo da mediação biográfica consiste nesse saber-fazer com o outro, denominado pela autora como heteroformação, e o saber-fazer sozinho, autoformação. Trata-se de um processo que envolve formador e adulto em formação em seus processos interativos. A mediação biográfica é essencial ao processo de escrita dos memoriais.
O uso de textos caracterizados como escritas de si aparece nos trabalhos de Nacarato (2010; 2017) e de Nacarato e Passeggi (2013). Nos trabalhos de 2010 e 2013, as autoras utilizam a expressão para se referir aos textos produzidos por graduandos do curso de Pedagogia, na disciplina Fundamentos e Metodologia do Ensino de Matemática. Eles criaram autobiografias e registros reflexivos a partir das temáticas discutidas na disciplina. Essa produção foi denominada de "escritas de si", e assim a autora a justifica: "São relatos autobiográficos e textos reflexivos que as alunas produzem ao longo do curso, os quais revelam suas crenças quanto à matemática e seu ensino, bem como as marcas que a disciplina lhes deixa ao longo da formação na escola básica" (NACARATO, 2010, p. 906). Já no último estudo (NACARATO, 2017), a autora utiliza a expressão para narrar sua experiência sobre formação de professores, a partir de sua vivência como formadora, nas últimas décadas. Ela narra sua trajetória como formadora e pesquisadora no campo da formação docente, refletindo como foi se constituindo nas aproximações com alguns conceitos que emergiram no cenário da formação docente, a partir da década de 1980.

As narrativas de aulas ou de práticas identificadas neste estudo referem-se aos textos produzidos por professores em contextos de trabalho em grupo. Foram identificados três textos: Marquesin e Nacarato (2011), Grando e Nacarato (2016) e Silva, Prado e Barbosa (2016).

Marquesin e Nacarato (2011) analisam narrativas de professoras dos anos iniciais sobre o ensino de geometria, num contexto de formação continuada na escola, na perspectiva do grupo colaborativo. As professoras produziram narrativas orais e escritas de suas aulas, as quais eram compartilhadas no grupo. As narrativas foram consideradas como estratégias de formação. 
Grando e Nacarato (2016) analisam narrativas de professoras do ciclo de alfabetização, participantes do Programa Observatório da Educação (Obeduc). Elas reconhecem o grupo como uma comunidade de investigação, na qual as narrativas elaboradas pelas professoras eram compartilhadas, e o conjunto dessa produção, segundo as autoras, constitui um campo de estudo sobre práticas de letramento matemático.

Silva, Prado e Barbosa (2016) também utilizam narrativas de práticas de professores envolvidos no Obeduc. Os autores analisam as "formas de desenvolver aulas de matemática (processo) e formas de escrever (produto) esboçadas em narrativas de aulas" (2016, p. 93), na perspectiva da aprendizagem situada e do conceito de comunidade de prática. As narrativas construídas pelos participantes eram discutidas entre os pares e depois foram publicadas no portal virtual do grupo de pesquisa.

Nesses três trabalhos, identificamos a concepção de produção de narrativas como prática de (auto)formação do professor, pois no ato da escrita o professor reflete sobre sua aula e sua prática e, ao compartilhar com os pares, possibilita aprendizagens recíprocas. Como afirmam Grando e Nacarato (2016, p. 144):

No interior das comunidades de investigação é possivel que o professor se transforme, transforme suas práticas escolares e também as institucionalizadas, por meio da reflexão, do estranhamento, do questionamento e do compartilhamento de práticas e ações no seu ambiente de trabalho. Quando no grupo há respeito mútuo, confiança compartilhada e ética nas relações estabelecidas, o professor se sente à vontade, se sente empoderado e ousa apresentar suas práticas, refletir, analisar e, até mesmo, questionar teorias.

Há um conjunto de nove estudos cujos pesquisadores tomam como objeto de análise narrativas produzidas a partir de entrevistas ou pelos próprios sujeitos da pesquisa. Dois estudos desse conjunto tomam as entrevistas como fonte de produção de dados: Ciríaco e Morelatti (2016) e Pereira e Nacarato (2017). Ciríaco e Morelatti (2016) utilizam narrativas de duas professoras dos anos iniciais do ensino fundamental sobre os desafios de aprender a ensinar matemática em seus primeiros anos de carreira. As narrativas foram escritas a partir de entrevistas semiestruturadas. Já a pesquisa de Pereira e Nacarato (2017), que teve como objetivo investigar o processo de constituição profissional de professores formadores na rede municipal de São Luís/Maranhão, utilizou a entrevista narrativa para compor as trajetórias desses formadores. As narrativas de trajetórias organizadas pelo pesquisador primeiro autor do texto - foram complementadas por discussões no grupo de discussão-reflexão para o processo de análise.

Dois trabalhos fazem referências a narrativas como fonte de dados para as pesquisas: Pamplona (2012) e Pereira (2018). Pamplona (2012) refere-se a narrativas biográficas criadas por cinco professores experientes que ensinam Estatística em cursos de Licenciatura em Matemática. O referencial teórico utilizado refere-se às comunidades de prática, e as narrativas tiveram origem em entrevistas concedidas pelos depoentes. Pereira (2018) não trabalhou exclusivamente no campo da Educação Matemática, pois utilizou-se da História Oral e de narrativas de professores bacharéis que atuam em cursos de licenciatura. Uma das entrevistadas atuava na Licenciatura em Matemática. 0 foco do texto centra-se na discussão e na análise dos procedimentos metodológicos criados para a pesquisa que toma as narrativas orais na perspectiva da História Oral.

Dois trabalhos referem-se à elaboração de narrativas no contexto de estágio supervisionado: Martinez e Moura (2017) e Carneiro (2015). Martinez e Moura (2017) têm como objeto de análise as narrativas de estudantes es- 
tagiários de um curso de Pedagogia, os quais registram as experiências relativas a aprender e ensinar Matemática. Utilizam-se do paradigma indiciário como abordagem analítica, buscando identificar e compreender, nas narrativas reflexivas, como estudantes produzem sentidos para as experiências de formação. Carneiro (2015) tomou como objeto de análise narrativas escritas de seis futuros professores no contexto do estágio supervisionado em matemática. A análise, segundo o autor, revelou que os graduandos, colocando-se na posição de professores, discutiram, refletiram e problematizaram diferentes aspectos que perpassam a profissão docente durante o estágio. Refletiram sobre a relação professor-aluno, apontando suas perspectivas sobre ensino e aprendizagem e discutindo conteúdos matemáticos.

Dois outros estudos utilizam narrativas nascidas no contexto da graduação: Silva (2013) e Julio e Silva (2018). Silva (2013) apresenta e discute estratégias elaboradas e aplicadas no âmbito da formação inicial de professores de matemática, as quais buscaram integrar recursos da História Oral e narrativas a abordagens pedagógicas problematizadoras na disciplina de Fundamentos da Matemática Elementar do curso de licenciatura em matemática. Julio e Silva (2018) tomam como fonte de dados as narrativas escritas e orais desenvolvidas por estudantes do curso de Pedagogia de uma universidade federal localizada no sul de Minas Gerais. Para os autores, a formação matemática inicia-se antes do ingresso na universidade, e é importante conhecer as trajetórias desses estudantes para contribuir no seu processo de formação. No texto, os autores também discutem o papel do professor formador no curso de Pedagogia e a presença das disciplinas voltadas a conteúdos matemáticos.

Finalmente, o trabalho de Passos, Oliveira e Gama (2013) desenvolveu-se no âmbito de um projeto no qual a participação dos professores era voluntária. No texto, as autoras buscam compreender aspectos envolvidos no processo reflexivo individual e coletivo, mobilizados por narrativas orais e escritas de professores e futuros professores, graduandos do curso de Pedagogia; as narrativas escritas eram discutidas nos encontros do grupo. Para compor o texto, as autoras analisam as narrativas de uma graduanda, possibilitando entender a cultura de aula de matemática por ela vivida e como ela se projeta como futura professora, implementando práticas diferenciadas das que vivenciou como estudante.

Com exceção dos estudos de Pereira e Nacarato (2017) e Passos, Oliveira e Gama (2013), que informam em seus textos que houve compartilhamento das narrativas produzidas, os demais não informam se houve ou não discussão/compartilhamento do material produzido.

Podemos nos questionar: qual é a finalidade de produzir narrativas? Apenas para gerar dados de pesquisa? Ou elas precisam ser consideradas como práticas de (auto)formação? Principalmente, se ponderarmos que a maioria delas foi elaborada em contextos de formação, a socialização pode ser tida como uma prática formativa. Evidentemente, pela literatura que utilizamos, a produção de narrativas ou, mesmo, a concessão de uma entrevista já se configura como um momento de reflexão por parte do narrador, que, ao refletir, pode produzir sentidos para a sua experiência; portanto, ela pode ser autoformadora. No entanto, essas narrativas ganham novos sentidos, quando discutidas pelos pares - seja no contexto de uma disciplina na graduação, seja num contexto de formação continuada. Assim, num contexto de Estágio Supervisionado, por exemplo, o compartilhamento de narrativas é fundamental como prática ou estratégia de formação. 
Chamou-nos a atenção o número significativo de nove estudos que se configuram como textos teóricos: pesquisas de sistematização da produção na área ou textos que discutem os aspectos teórico-metodológicos da pesquisa com narrativas e suas relações com a metodologia da História Oral.

Três trabalhos são de sistematizações de pesquisas: Nacarato (2015), Gama e Nakayama (2016) e Belo et al (2017). O trabalho de Nacarato (2015) é uma sistematização dos trabalhos realizados no grupo de pesquisa Histórias de Formação de Professores que Ensinam Matemática (Hifopem), vinculado ao Programa de Pós-Graduação da Universidade São Francisco. A autora destaca dois dispositivos de produção de dados: entrevista narrativa e grupo de discussão, tomando como corpus de análise as dissertações e as teses produzidas no contexto do grupo, destacando os processos de produção e análise dos dados.

Gama e Nakayama (2016) utilizaram o método (auto)biográfico e as narrativas de formação como movimento de investigação-formação num estudo meta-analítico que analisou as produções no âmbito do Programa Observatório da Educação, vinculado à UFSCar. O estudo teve como objetivo evidenciar os tipos de práticas que potencializam o desenvolvimento profissional docente.

Belo et al (2017) fazem um balanço das pesquisas produzidas na Região Norte que têm como foco as narrativas. Essa compilação faz parte do projeto "Mapeamento da pesquisa acadêmica brasileira sobre o professor que ensina Matemática: período 2001-2012" (FIORENTINI; PASSOS; LIMA, 2016). Os autores concluem que a produção ocorreu em uma diversidade de contextos e apontam para a necessidade de entendimento das abordagens teórico-metodológicas para essa modalidade de pesquisa.

Consideramos importantes esses trabalhos de sistematização, pois contribuem para o co- nhecimento da produção numa determinada área de investigação e estimulam novas pesquisas, principalmente quando apontam tendências e lacunas na temática investigada.

Outro conjunto de seis trabalhos discute aspectos teórico-metodológicos do uso de narrativas e sua relação com a metodologia da História Oral. Todos os pesquisadores envolvidos nessa discussão são membros do Grupo de História Oral em Educação Matemática (GHOEM), da Unesp/Rio Claro, que atuam ou tiveram sua formação nesse grupo. São eles: Cury (2010), Gomes (2012; 2015; 2018), Tizzo, Flugge e Silva (2015) e Xavier e Silva (2015).

Cury (2010) apresenta reflexões sobre o uso da análise narrativa como artifício para a interpretação de dados biográficos/historiográficos de pesquisas em História da Educação (Matemática). Ele parte das ideias de Walter Benjamin, Jorge Larrosa e Benedito Nunes, para analisar os vínculos que ligam narrativas, ficção e historiografia. Utiliza o conceito de análise narrativa de Antonio Bolívar.

A pesquisadora Maria Laura Magalhães Gomes produziu três pesquisas em que analisa as relações entre narrativas (auto)biográficas, a metodologia da História Oral e a História da Educação Matemática. Em seu primeiro trabaIho, examina as possibilidades de conexão entre escrita autobiográfica e História da Educação Matemática. A autora discute concepções de escrita autobiográfica, apresenta um panorama de seu desenvolvimento histórico, bem como a tipologia dos escritos autobiográficos. Discute, ainda, a natureza teórico-metodológica relativa às principais questões a considerar nas pesquisas historiográficas que os utilizam como fonte ou como objeto (GOMES, 2012). Em Gomes (2015), a autora discute as relações entre História e narrativa e o papel das narrativas autobiográficas, postulando que, nas narrativas autobiográficas, há que se considerar a subjetividade do autor, o papel do intérprete, a 
convivência de tempos distintos e as relações narrativa-autor. No trabalho posterior (GOMES, 2018), a partir da análise do livro de memórias de Carlos Galante (1920-2003), ela discute questões relacionadas às dimensões teóricometodológicas que orientam a pesquisa com fontes autobiográficas.

Essa pesquisadora também é coautora de outro texto (VIEIRA; GOMES, 2014), que se apoia na metodologia da História Oral, aliada ao conceito de narrativa de Antonio Bolivar. As autoras, utilizando a metodologia da HO, entrevistaram dez professores para analisar o papel desempenhado pelos livros didáticos na formação dos docentes para as práticas pedagógicas relacionadas aos conhecimentos matemáticos.

Tizzo, Flugge e Silva (2015) partem de duas pesquisas vinculadas a um projeto maior e buscam analisar as contribuições, as limitações e as potencialidades da HO e a compreensão de como a abordagem narrativa e da HO pode contribuir em disciplinas de conteúdos matemáticos no curso de Pedagogia. Os autores defendem a abordagem da História Oral como uma prática proficua para auxiliar processos formativos voltados ao futuro professor (de Matemática), pois permite a inscrição do percurso pessoal e profissional dos licenciandos na história.

A pesquisa de Xavier e Silva (2015) situa-se no contexto do Programa Institucional de Bolsas de Iniciação à Docência (Pibid) para a formação de professores de Matemática, a partir de narrativas (auto)biográficas de ex-bolsistas. O foco do artigo centra-se na discussão e na análise dos procedimentos metodológicos criados para a pesquisa que toma as narrativas orais na perspectiva da metodologia da História Oral, tendo como referência os pressupostos construídos pelo GHOEM.

$O$ fato desses pesquisadores estarem vinculados ao GHOEM pode justificar a ênfase que colocam nessa discussão sobre as possiveis aproximações entre o método (auto) biográfico, do qual Antonio Bolivar - pesquisador espanhol bastante citado e referência para o grupo - é considerado um representante e os procedimentos metodológicos da História Oral, tradição do GHOEM e cujo arcabouço teórico-metodológico construído coletivamente pelo grupo é referência nacional. Nesse sentido, concordamos com as conclusões de Nacarato, Oliveira e Fernandes (2017), ao analisarem a produção de dissertações e teses, no período de 2002-2012, de que as aproximações entre esses dois campos de investigação - abordagens autobiográficas e história oral - vão além das questões metodológicas, mas se constituem em espaços-tempo para a voz dos professores e futuros professores, reconhecendo-os como protagonistas do seu fazer docente ou sujeitos da experiência, que refletem e produzem sentidos para suas trajetórias de formação e atuação.

\section{Algumas sínteses (in)conclusivas}

Ao realizar a presente pesquisa, sabíamos de antemão de suas dificuldades, limitações e riscos. Dificuldades pelo número de trabalhos identificados - não imaginávamos tal produção dos educadores matemáticos; limitações, porque, no espaço delimitado para um artigo, não é possível, muitas vezes, fazer uma descrição detalhada de todos os trabalhos e, portanto, reconhecemos que esta sistematização tem seus limites; riscos, pois temos certeza de que muitos estudos ficaram fora desta revisão, mesmo considerando nossas fontes, o que se torna mais amplo, se observarmos o montante de periódicos nacionais. Assim, essa foi uma sistematização possivel e ela teve como lentes analíticas nossa constituição como pesquisadoras biográficas pelos caminhos já traçados, 
teórica e metodologicamente, no nosso grupo de pesquisa.

Ao retomarmos nossa questão de investigação - "O que se tem produzido de pesquisas (auto)biográficas no campo da Educação Matemática?" -, podemos traçar algumas sínteses, diríamos (in)conclusivas. Um primeiro dado que nos chama a atenção é a polissemia que envolve os termos desse campo de inquérito, já apontada por Souza (2010). Há uma gama de terminologias que, muitas vezes, dificulta a classificação da pesquisa numa determinada modalidade. Aliás, entendemos que toda classificação é problemática, pois ela é feita sob a interpretação do pesquisador e pode não ser consensual com os autores do trabalho.

Outra constatação refere-se ao movimento da comunidade de investigadores para compreender essa abordagem metodológica, pois é grande o número de trabalhos teóricos que, ou sistematizaram o que já foi produzido, ou buscaram construir aportes teóricos e metodológicos para esse campo de investigação. Daí podermos afirmar que se trata de um campo em construção e, por isso, ainda é possivel identificar fragilidades em alguns trabalhos. Nem todos os autores apresentam ao leitor quais as concepções e as matrizes de referência para as pesquisas desenvolvidas; alguns textos afirmam tratar-se de pesquisa (auto) biográfica, mas sem discussões teóricas da temática. Assim, também faltam elementos que situem o contexto de produção de dados; que explicitem o processo de entrevista ou escrita dos sujeitos, ou de transformação de entrevistas em narrativas; ou que indiquem se houve devolutiva aos pesquisados, dentre outros. Alguns textos deste corpus, como o de Nacarato (2015) ou o de Gomes (2015), apontam para alguns cuidados metodológicos e, principalmente, éticos. Se, historicamente, os professores foram silenciados pelas políticas públicas, a pesquisa (auto)biográfica pode se constituir em possibilidades de se colocar à escuta desses profissionais e reconhecê-los como protagonistas de suas práticas. Assim, não apoiamos pesquisas que tomam depoimentos e narrativas de professores apenas como dados para a pesquisa, sem a devida devolutiva tanto da transcrição de entrevistas, por exemplo, quanto da própria pesquisa concluída.

As narrativas se apresentam como fonte de significação de experiências vividas na escola, como estudantes ou como docentes. Para Nacarato (2010, p. 928), quando tomada como objeto de problematização e reflexão, a escrita autobiográfica pode contribuir para o rompimento de práticas e crenças tradicionais do ensino da matemática, permitindo ao (futuro) professor (re)significar suas aprendizagens e construir um repertório de saberes que subsidiam a sua atuação em outra perspectiva, diferente daquelas que vivenciaram. Além disso, tais narrativas trazem os sentidos que cada sujeito atribui ao vivido, como também a história de um contexto específico, as ideias de uma coletividade profissional. Seu compartilhamento - entre os pares ou com o próprio pesquisador - se constitui em prática de formação que precisa ser valorizada.

Outro cuidado refere-se ao modo de tratamento dos dados, o que exige respeito do pesquisador com os depoentes, mas também compromisso ético de esclarecer o processo analítico utilizado. Concordamos com Gomes (2012, p. 132):

Como acontece com qualquer documento, a interpretação do escrito autobiográfico é subjetiva, parcial e situada. As mesmas passagens poderiam ser compreendidas e/ou interpretadas de forma distinta por leitores diferentes, que realizariam análises também subjetivas, parciais e situadas, fundadas em suas vivências e repertórios socioculturais. Em um mesmo texto, um leitor poderia selecionar como mais significativos trechos diante dos quais outro intérprete sentiria indiferença ou mesmo rejeição. 
Da mesma forma, um trabalho como este de sistematização pode ter múltiplas interpretações. Reafirmamos, essa foi uma possivel. Acreditamos que ela possa contribuir para novos mapeamentos e estados da arte.

\section{Referências}

BELO, Edileusa do Socorro Valente et al. Histórias de vida de professores que ensinam matemática: um olhar sobre as pesquisas acadêmicas brasileiras produzidas na região Norte, de 2001 a 2012. Revista Brasileira de Pesquisa (Auto)Biográfica, Salvador, v. 2, n. 6, p. 719-740, set./dez. 2017. Disponivel em: <https:// www.revistas.uneb.br/index.php/rbpab/ article/view/3678>. Acesso em: 22 jan. 2019.

CARNEIRO, Reginaldo Fernando. Narrativas no estágio supervisionado em matemática como uma possibilidade para discussão da profissão docente. In: REUNIÃO NACIONAL DA ANPED, 37., 2015, UFSC Florianópolis. Anais... Florianópolis: ANPEd, 2015. p. 1-17.

CIRÍACO, Klinger Teodoro; MORELATTI, Maria Raquel Miotto. Problemas experienciados por professoras iniciantes em aulas de matemática. Revista Eletrônica de Educação, v. 10, n. 3, p. 267-280, 2016. Disponivel em: <http://www.reveduc.ufscar.br/index.

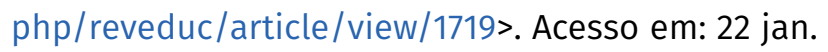
2019.

CURY, Fernando Guedes. Análise narrativa em trabaIhos de História da Educação Matemática: algumas considerações. Bolema, Rio Claro (SP), v. 23, n. 35A, p. 59-73, abr. 2010. Disponivel em: <https://www.redalyc.org/articulo.oa?id=291221892004>. Acesso em: 22 jan. 2019.

D'AMBROSIO, Beatriz Silva. O professor-pesquisador diante da produção escrita dos alunos. Revista Educação PUC-Campinas, Campinas, v. 18, n. 3, p. 249-258, set./dez., 2013. Disponivel em: <http:// periodicos.puc-campinas.edu.br/seer/index.php/ reveducacao/article/view/2362/1834>. Acesso em: 22 jan. 2019.

FIORENTINI, Dario; PASSOS, Cármen Lúcia B.; LIMA, Rosana Catarina R. (Org.). Mapeamento da pes- quisa acadêmica brasileira sobre o professor que ensina Matemática: período 2001-2012. Campinas, SP: FE-Unicamp, 2016. v. 1. 488p. E-book. Disponivel em: <https://www.fe.unicamp.br/pf-fe/pagina_basica/58/e-book-mapeamento-pesquisa-pem.pdf>. Acesso em: 15 jan. 2019.

GAMA, Renata Prenstteter; NAKAYAMA, Bárbara C. M. Sicardi. Rede colaborativa de professores que ensinam Matemática: articulando ensino, pesquisa e extensão. Zetetiké, FE/Unicamp; FEUFF, v. 24, n. 45, p. 59-74, jan./abr.2016. Disponivel em: <https://periodicos.sbu.unicamp.br/ojs/index.php/zetetike/ article/view/8646529>. Acesso em: 22 jan. 2019.

GEPFPM. Grupo de Estudo e Pesquisa sobre Formação de Professores de Matemática e as revisões sistemáticas. In: OLIVEIRA, A. M. P.; ORTIGÃO, M. I. R. (Orgs.). Abordagens teóricas e metodológicas nas pesquisas em educação matemática. Livro Eletrônico. Brasília, DF: SBEM, 2018. p. 234-254. (Coleção SBEM, 13).

GOMES, Maria Laura Magalhães. Escrita autobiográfica e História da Educação Matemática. Bolema, Rio Claro, SP, v. 26, n. 42A, p. 105-137, abr. 2012. Disponivel em: <http://www.scielo.br/scielo.php?pid $=$ S0103-636X2012000100007\& script=sci_abstrac t\&tlng=pt>. Acesso em: 22 jan. 2019.

GOMES, Maria Laura Magalhães. Narrativas autobiográficas e pesquisa em História da Educação Matemática: notas metodológicas. Perspectivas da Educação Matemática, UFMS, v. 8, número temático, p. 587-606, 2015. Disponível em: <http://seer.ufms.br/ index.php/pedmat/article/view/1465>. Acesso em: 22 jan. 2019.

GOMES, Maria Laura Magalhães. Elementos de uma história de formação docente: as memórias de um professor de Matemática. Bolema, Rio Claro, SP, v. 32, n. 60, p. 191- 211, abr. 2018. Disponivel em: <http:// www.scielo.br/scielo.php?script=sci_abstract \& pi$d=S 0103=636-2018000100191 X \&$ lng $=$ pt $\&$ nrm $=i \&$ tlng pt>. Acesso em: 22 jan. 2019.

GRANDO, Regina Célia; NACARATO, Adair Mendes. Compartilhamento de práticas formativas em matemática escolar por professoras. Zetetiké, FE/Unicamp; FEUFF, v. 24, n. 45, p. 141-156, jan./abr. 2016. 
Disponivel em: <https://periodicos.sbu.unicamp. br/ojs/index.php/zetetike/article/view/8646534>. Acesso em: 22 jan. 2019.

JULIO, Rejane Siqueira; SILVA, Guilherme Henrique Gomes da. Compreendendo a formação matemática de futuros pedagogos por meio de narrativas. Bolema, Rio Claro, SP, v. 32, n. 62, p. 1012-1029, dez. 2018. Disponivel em: <http://www.scielo.br/pdf/bolema/ v32n62/1980-4415-bolema-32-62-1012.pdf>. Acesso em: 22 jan. 2019.

MARQUESIN, Denise Filomena Bagne; NACARATO, Adair Mendes. A prática do saber e o saber da prática em geometria: análise do movimento vivido por um grupo de professoras dos anos iniciais do Ensino Fundamental. Zetetiké, Cempem / FE/Unicamp, v. 19, n. 35, p. 103-137, jan./jun. 2011. Disponivel em: <https://periodicos.sbu.unicamp.br/ojs/index.php/ zetetike/article/view/8646647>. Acesso em: 22 jan. 2019.

MARTINEZ, Adriana Ofretorio de Oliveira Martin; MOURA, Anna Regina Lanner de. Uma reflexão sobre o uso da escrita em narrativa na formação inicial de estudantes de Pedagogia para ensinar matemática. Perspectivas da Educação Matemática, INMA/ UFMS, v. 10, n. 22, p. 327-348, 2017. Disponivel em: <http://seer.ufms.br/index.php/pedmat/article/ view/1608>. Acesso em: 22 jan. 2019.

MARTINS, Rosana Maria; ROCHA, Simone Albuquerque. Tornando-se professora: narrativas sobre os processos de constituição da identidade docente de licenciandos em matemática. In: REUNIÃO NACIONAL DA ANPED, 36., 2013, UFG-Goiânia. Anais... Goiânia: ANPEd, 2013. p. 1-15.

NACARATO, Adair Mendes. A formação matemática das professoras das séries iniciais: a escrita de si como prática de formação. Bolema, Rio Claro, SP, v. 23 , n. 37, p. 905-930, dez. 2010. Disponivel em: <https:// www.redalyc.org/pdf/2912/291221915004. pdf>. Acesso em: 22 jan. 2019.

NACARATO, Adair Mendes. As narrativas de vida como fonte para a pesquisa autobiográfica em Educação Matemática. Perspectivas da Educação Matemática, INMA/UFMS, v. 8, número temático, p. 448-467, 2015. Disponivel em: <http://seer.ufms.br/ index.php/pedmat/article/view/1440>. Acesso em: 22 jan. 2019.

NACARATO, Adair Mendes. Práticas de formação e de pesquisa do professor que ensina matemática: uma construção narrativa. Perspectivas da Educação Matemática, INMA/UFMS, v. 10, n. 24, p. 768-779, 2017. Disponivel em: <http://seer.ufms.br/index. php/pedmat/article/view/5536>. Acesso em: 22 jan. 2019.

NACARATO, Adair Mendes; OLIVEIRA, Andréia Maria Pereira de; FERNANDES, Déa Nunes. Histórias da formação e de professores que ensinam Matemática: possíveis aproximações teórico-metodológicas. Zetetiké, Campinas, SP, v. 25, n. 1, p. 46-74, jan./abr. 2017.

NACARATO, Adair Mendes; PASSEGGI, Maria da Conceição. Narrativas autobiográficas produzidas por futuras professoras: representações sobre a matemática escolar. Revista Educação PUC-Campinas, Campinas, SP, v. 18, n. 3, p. 287-299, set./dez. 2013.

NACARATO, Adair Mendes; PASSOS, Cármen Lúcia Brancaglion; SILVA, Heloisa da. Narrativas na pesquisa em Educação Matemática: caleidoscópio teórico e metodológico. Bolema, Rio Claro, SP, v. 28, n. 49, p. 701-716, ago. 2014.

PAMPLONA, Admur Severino. A formação estatística e pedagógica do professor de Matemática. Zetetiké, FE/Unicamp, v. 20, n. 37, p. 85-99, jan./jun. 2012. Disponivel em: <https://periodicos.sbu.unicamp. br/ojs/index.php/zetetike/article/view/8646637>. Acesso em: 22 jan. 2019.

PASSEGGI, Maria da Conceição. A formação do formador na abordagem autobiográfica. A experiência nos memoriais de formação. In: SOUZA, E. C.; ABRAHÃO, M. H. M. B. (Orgs.). Tempos, narrativas e ficção: a invenção de si. Porto Alegre: EDIPUCRS, 2006. p. 203-218.

PASSEGGI, Maria da Conceição. A mediação biográfica. Acompanhar adultos em processos-projetos de si. In: Portal do Envelhecimento. Espaço memória, 2007. Disponivel em: <http://www.portaldoenvelhecimento.com.br/mediacao-biografica-acompanhar -adultos-em-processos-projetos-de-si/>. Acesso em: jun. 2015. 
PASSOS, Cármen Lúcia B.; OLIVEIRA, Rosa Maria M. Anunciato; GAMA, Renata Pranstetter. Narrativas em grupo de professores e licenciandos: ressignificando a aprendizagem da matemática. Revista Educação PUC-Campinas, Campinas, SP, v .18, n. 3, p. 327339, set./dez. 2013.

PEREIRA, Carlos André Bogéa; NACARATO, Adair Mendes. A formação de formadores de professores que ensinam matemática: o caso de São Luís/MA. In: REUNIÃO NACIONAL DA ANPEd, 38., 2017, São Luís. Anais... São Luís/MA: UFMA; ANPEd, 2017. p. 1-17.

PEREIRA, Diego Carlos. Processo de formação continuada: narrativas de professores bacharéis que atuam em cursos de licenciatura. Revista Eletrônica de Educação, v. 12, n. 3, p. 741-756, set./dez. 2018. Disponível em: <http://www.reveduc.ufscar.br/index.php/reveduc/article/view/2454>. Acesso em: 22 jan. 2019.

ROSA, Fernanda Malinosky C. da; BARALDI, Ivete Maria. O uso de narrativas (auto)biográficas como uma possibilidade de pesquisa da prática de professores acerca da Educação (Matemática). Bolema, Rio Claro, SP, v. 29, n. 53, p. 936-954, dez. 2015. Disponível em: <http://www.scielo.br/pdf/bolema/ v29n53/1980-4415-bolema-29-53-0936.pdf>. Acesso em: 22 jan. 2019.

SILVA, Diva Souza. Trajetórias de formação de professores em Matemática a distância: entre saberes, experiências e narrativas. In: REUNIÃO NACIONAL DA ANPEd, 33., 2011, Caxambu/MG. Anais... Caxambu/ MG: ANPEd, 2011. p. 1-18.

SILVA, Heloisa da. Integrando história oral e narrativas a abordagens pedagógicas problematizadoras na formação inicial de professores de matemática.

Revista Educação PUC-Campinas, Campinas, SP, v .18, n. 3, p. 269-285, set./dez. 2013.

SILVA, Lilian Aragão da; PRADO, Airam da Silva; BARBOSA, Jonei Cerqueira. Narrativas de aulas de matemática: reificações de comunidades de prática. Zetetiké, FE/Unicamp; FEUFF, v. 24, n. 45, p. 93-107, jan./abr. 2016. Disponível em: <https://periodicos. sbu.unicamp.br/ojs/index.php/zetetike/article/ view/8646531>. Acesso em: 22 jan. 2019.

SOUSA, Maria do Carmo de. Escritas reflexivas de professores que ensinam Matemática enquanto desenvolvem produtos. Zetetiké, FE/Unicamp; FEUFF, v. 24, n. 45, p. 43-58, jan./abr. 2016. Disponível em: <https://periodicos.sbu.unicamp.br/ojs/index.php/ zetetike/article/view/8646528>. Acesso em: 22 jan. 2019.

SOUZA, Elizeu Clementino de. Pesquisa narrativa, (auto)biografias e História Oral: ensino, pesquisa e formação em Educação Matemática. Ciências Humanas e Sociais em Revista, Rio de Janeiro, v. 32, n. 2, p. 13-27, jul./dez. 2010. Disponível em: <http:// www.ufrrj.br/SEER/index.php?journal=chsr\&page=article\&op=view \&path\%5B\%5D=809>. Acesso em: 22 jan. 2019.

TIZZO, Vinícius Sanches; FLUGGE, Flávia Cristina Gomes; SILVA, Heloisa da. Práticas possiveis com a História Oral na formação inicial de professores (de Matemática). Bolema, Rio Claro, SP, v. 29, n. 53, p. 887-908, dez. 2015.

VIEIRA, Gláucia Marcondes; GOMES, Maria Laura Magalhães. Livros didáticos e formação de professores que ensinam Matemática nos anos iniciais do Ensino Fundamental. Educar em Revista, Curitiba, n. 54, p. 257-273, out./dez. 2014. Disponivel em: <https:// revistas.ufpr.br/educar/article/view/34325/23922>. Acesso em: 22 jan. 2019.

XAVIER, Ana Claudia Molina Zaqueu; SILVA, Heloisa da. Produção e Análise de Narrativas Escritas ou Orais: possibilidades na investigação sobre formação de professores de matemática. Perspectivas da Educação Matemática, UFMS, v. 8, número temático, p. 709-726, 2015. Disponível em: <http://seer.ufms. br/index.php/pedmat/article/view/1467>. Acesso em: 22 jan. 2019.

Recebido em: 30.01.2019 Aprovado em: 30.03.2019 
Adair Mendes Nacarato é Doutora em Educação pela FE/Unicamp. Professora da Universidade São Francisco. Docente do Programa de Pós-Graduação Stricto Sensu em Educação. Grupo de Pesquisa: Histórias de Formação de Professores que Ensinam Matemática (Hifopem). e-mail: adamn@terra.com.br

Av. Senador Lacerda Franco, 360 - Centro. Itatiba/SP.

CEP 13250-400. Telefone: (19)99733-2714

Kátia Gabriela Moreira é doutoranda e Mestre em Educação do Programa de Pós-Graduação Stricto Educação da Universidade São Francisco. Grupo de Pesquisa: Histórias de Formação de Professores que Ensinam Matemática (Hifopem). e-mail: ktiagabriela@hotmail.com

Av. Senador Lacerda Franco, 360 - Centro. Itatiba/SP.

CEP 13250-400 Telefone: (11)971799154

Iris Aparecida Custódio é doutoranda e Mestre em Educação do Programa de Pós-Graduação Stricto Educação da Universidade São Francisco. Grupo de Pesquisa: Histórias de Formação de Professores que Ensinam Matemática (Hifopem). e-mail: irisapcustodio@gmail.com

Av. Senador Lacerda Franco, 360 - Centro. Itatiba/SP.

CEP 13250-400 Telefone: (11)94145-5741

\section{APÊNDICE 1}

Quadro 3 - Relação de trabalhos publicados no GT19 Educação Matemática e periódicos

\begin{tabular}{|c|c|c|}
\hline Ano & Título & Autores \\
\hline \multicolumn{3}{|c|}{ GT19 EDUCAÇÃO MATEMÁTICA/ANPED } \\
\hline 2011 & $\begin{array}{l}\text { Trajetórias de formação de professores em } \\
\text { Matemática à distância: entre saberes, experiências e } \\
\text { narrativas }\end{array}$ & Diva Souza Silva - UFU \\
\hline 2013 & $\begin{array}{l}\text { Tornando-se professora: narrativas sobre os } \\
\text { processos de constituição da identidade docente de } \\
\text { licenciandos em Matemática }\end{array}$ & $\begin{array}{l}\text { Rosana Maria Martins - UFMT } \\
\text { Simone Albuquerque da Rocha - UFMT }\end{array}$ \\
\hline 2015 & $\begin{array}{l}\text { Narrativas no estágio supervisionado em Matemática } \\
\text { como uma possibilidade para discussão da profissão } \\
\text { docente }\end{array}$ & Reginaldo Fernando Carneiro - UFJF \\
\hline 2017 & $\begin{array}{l}\text { A formação de formadores de professores que } \\
\text { ensinam Matemática: o caso de São Luís/MA }\end{array}$ & $\begin{array}{l}\text { Carlos André Bogéa Pereira - USF } \\
\text { Adair Mendes Nacarato - USF }\end{array}$ \\
\hline \multicolumn{3}{|c|}{ BOLETIM DE EDUCAÇÃO MATEMÁTICA - BOLEMA } \\
\hline \multirow[t]{2}{*}{2010} & $\begin{array}{l}\text { Análise Narrativa em Trabalhos de História da } \\
\text { Educação Matemática: algumas considerações }\end{array}$ & $\begin{array}{l}\text { Fernando Guedes Cury - Unesp/Rio } \\
\text { Claro }\end{array}$ \\
\hline & $\begin{array}{l}\text { A Formação Matemática das Professoras das Séries } \\
\text { Iniciais: a escrita de si como prática de formação }\end{array}$ & Adair Mendes Nacarato - USF \\
\hline 2012 & $\begin{array}{l}\text { Escrita Autobiográfica e História da Educação } \\
\text { Matemática }\end{array}$ & Maria Laura Magalhães Gomes - UFMG \\
\hline \multirow[b]{2}{*}{2015} & $\begin{array}{l}\text { O uso de narrativas (auto)biográficas como uma } \\
\text { possibilidade de pesquisa da prática de professores } \\
\text { acerca da Educação (Matemática) Inclusiva }\end{array}$ & $\begin{array}{l}\text { Fernanda Malinosky C. da Rosa - } \\
\text { Unesp/Rio Claro } \\
\text { Ivete Maria Baraldi - Unesp/Rio Claro }\end{array}$ \\
\hline & $\begin{array}{l}\text { Práticas Possíveis com a História Oral na Formação } \\
\text { Inicial de Professores (de Matemática) }\end{array}$ & $\begin{array}{l}\text { Vinícius Sanches Tizzo - Unesp/Rio } \\
\text { Claro } \\
\text { Flávia Cristina Gomes Flugge - Unesp/ } \\
\text { Rio Claro } \\
\text { Heloisa da Silva - Unesp/Rio Claro }\end{array}$ \\
\hline
\end{tabular}




\begin{tabular}{|c|c|c|}
\hline \multirow{2}{*}{2018} & $\begin{array}{l}\text { Elementos de uma História de Formação Docente: as } \\
\text { memórias de um professor de Matemática }\end{array}$ & Maria Laura Magalhães Gomes - UFMG \\
\hline & $\begin{array}{l}\text { Compreendendo a Formação Matemática de Futuros } \\
\text { Pedagogos por meio de Narrativas }\end{array}$ & $\begin{array}{l}\text { Rejane Siqueira Julio - Unifal } \\
\text { Guilherme Henrique Gomes da Silva - } \\
\text { Unifal }\end{array}$ \\
\hline \multicolumn{3}{|c|}{ REVISTA EDUCAÇÃO PUC CAMPINAS } \\
\hline \multirow{7}{*}{2013} & $\begin{array}{l}\text { Narrativas autobiográficas produzidas por futuras } \\
\text { professoras: representações sobre a Matemática } \\
\text { escolar }\end{array}$ & $\begin{array}{l}\text { Adair Mendes Nacarato - USF } \\
\text { Maria da Conceição Passeggi - UFRN }\end{array}$ \\
\hline & $\begin{array}{l}\text { O professor-pesquisador diante da produção escrita } \\
\text { dos alunos }\end{array}$ & $\begin{array}{l}\text { Beatriz Silva D'Ambrosio - Miami } \\
\text { University }\end{array}$ \\
\hline & $\begin{array}{l}\text { Narrativas em grupo de professores e licenciandos: } \\
\text { ressignificando a aprendizagem da Matemática }\end{array}$ & $\begin{array}{l}\text { Cármen Lúcia Brancaglion Passos } \\
\text { UFSCar } \\
\text { Rosa Maria Moraes Anunciato de } \\
\text { Oliveira - UFSCar } \\
\text { Renata Prenstteter Gama - UFSCar }\end{array}$ \\
\hline & $\begin{array}{l}\text { O processo de adesão de professoras dos anos } \\
\text { iniciais ao uso de narrativas na formação docente em } \\
\text { Matemática }\end{array}$ & $\begin{array}{l}\text { Maria Auxiliadora Bueno Andrade } \\
\text { Megid- PUCCampinas }\end{array}$ \\
\hline & $\begin{array}{l}\text { Integrando história oral e narrativas a abordagens } \\
\text { pedagógicas problematizadoras na formação inicial } \\
\text { de professores de Matemática }\end{array}$ & Heloisa da Silva - Unesp-Rio Claro \\
\hline & $\begin{array}{l}\text { O papel das narrativas na aprendizagem da docência: } \\
\text { um enfoque no aspecto das interaçôes humanas }\end{array}$ & José Antônio Araújo Andrade - UFLA \\
\hline & $\begin{array}{l}\text { Narrativas na investigação em história da educação } \\
\text { Matemática }\end{array}$ & Luzia Aparecida de Souza - UFMS \\
\hline \multicolumn{3}{|c|}{ ZETETIKÉ - FE/UNICAMP } \\
\hline 2011 & $\begin{array}{l}\text { A prática do saber e o saber da prática em Geometria: } \\
\text { análise do movimento vivido por um grupo de } \\
\text { professoras dos anos iniciais do Ensino Fundamental }\end{array}$ & $\begin{array}{l}\text { Denise Filomena Bagne Marquesin,-- } \\
\text { Fac.Anhanguera } \\
\text { Adair Mendes Nacarato - USF }\end{array}$ \\
\hline 2012 & $\begin{array}{l}\text { A formação estatística e pedagógica do professor de } \\
\text { Matemática }\end{array}$ & Admur Severino Pamplona - UFMT \\
\hline \multirow{4}{*}{2016} & $\begin{array}{l}\text { Escritas reflexivas de professores que ensinam } \\
\text { Matemática enquanto desenvolvem produtos } \\
\text { educacionais coletivamente }\end{array}$ & Maria do Carmo de Sousa - UFSCar \\
\hline & $\begin{array}{l}\text { Rede colaborativa de professores que ensinam } \\
\text { Matemática: articulando ensino, pesquisa e extensão }\end{array}$ & $\begin{array}{l}\text { Renata Prenstteter Gama - UFSCar } \\
\text { Bárbara C. M. Sicardi Nakayama - } \\
\text { UFSCar }\end{array}$ \\
\hline & $\begin{array}{l}\text { Narrativas de aulas de Matemática: reificações de } \\
\text { comunidades de prática }\end{array}$ & $\begin{array}{l}\text { Lilian Aragão da Silva - UFRB } \\
\text { Airam da Silva Prado - UFBA } \\
\text { Jonei Cerqueira Barbosa - UFBA }\end{array}$ \\
\hline & $\begin{array}{l}\text { Compartilhamento de práticas formativas em } \\
\text { Matemática escolar por professoras alfabetizadoras }\end{array}$ & $\begin{array}{l}\text { Regina Célia Grando - USF } \\
\text { Adair Mendes Nacarato - USF }\end{array}$ \\
\hline 2017 & $\begin{array}{l}\text { Histórias da formação e de professores que ensinam } \\
\text { Matemática: possiveis aproximações teórico- } \\
\text { metodológicas }\end{array}$ & $\begin{array}{l}\text { Adair Mendes Nacarato - USF } \\
\text { Andréia Maria Pereira de Oliveira - UFBA } \\
\text { Déa Nunes Fernandes - IFMA }\end{array}$ \\
\hline \multicolumn{3}{|c|}{ PERSPECTIVAS EM EDUCAÇÃO MATEMÁTICA - UFMS } \\
\hline 2015 & $\begin{array}{l}\text { Produção e Análise de Narrativas Escritas ou Orais: } \\
\text { possibilidades na investigaçãa sobre formação de } \\
\text { professores de Matemática }\end{array}$ & $\begin{array}{l}\text { Ana Claudia Molina Zaqueu Xavier - } \\
\text { Unesp Rio Claro } \\
\text { Heloisa Silva - Unesp Rio Claro }\end{array}$ \\
\hline
\end{tabular}




\begin{tabular}{|c|c|c|}
\hline 2015 & $\begin{array}{l}\text { Narrativas Autobiográficas e Pesquisa em História da } \\
\text { Educação Matemática: notas metodológicas }\end{array}$ & Maria Laura Magalhães Gomes - UFMG \\
\hline 2015 & $\begin{array}{l}\text { As narrativas de vida como fonte para a pesquisa } \\
\text { autobiográfica em Educação Matemática }\end{array}$ & Adair Mendes Nacarato - USF \\
\hline 2017 & $\begin{array}{l}\text { Uma Reflexão sobre o Uso da Escrita em Narrativa na } \\
\text { Formação Inicial de Estudantes de Pedagogia para } \\
\text { Ensinar Matemática }\end{array}$ & $\begin{array}{l}\text { Adriana Ofretorio de Oliveira Martin } \\
\text { Martinez - Unicamp } \\
\text { Anna Regina Lanner de Moura - } \\
\text { Unicamp }\end{array}$ \\
\hline 2017 & $\begin{array}{l}\text { Práticas de formação e de pesquisa do professor que } \\
\text { ensina Matemática: uma construção narrativa }\end{array}$ & Adair Mendes Nacarato - USF \\
\hline \multicolumn{3}{|c|}{ REVISTA ELETRÔNICA DE EDUCAÇÃO - REVEDUC - UFSCar } \\
\hline 2016 & $\begin{array}{l}\text { Problemas experienciados por professoras iniciantes } \\
\text { em aulas de Matemática }\end{array}$ & $\begin{array}{l}\text { Klinger Teodoro Ciríaco - UFMS } \\
\text { Maria Raquel Miotto Morelatti - Unesp } \\
\text { Presidente Prudente }\end{array}$ \\
\hline 2018 & $\begin{array}{l}\text { Processo de formação continuada: narrativas de } \\
\text { professores bacharéis que atuam em cursos de } \\
\text { licenciatura }\end{array}$ & Diego Carlos Pereira - Unesp Rio Claro \\
\hline \multicolumn{3}{|c|}{ REVISTA BRASILEIRA DE PESQUISA (AUTO)BIOGRÁFICA - UNEB } \\
\hline 2017 & $\begin{array}{l}\text { Histórias de vida de professores que ensinam } \\
\text { Matemática: um olhar sobre as pesquisas acadêmicas } \\
\text { brasileiras produzidas na região Norte, de } 2001 \text { a } 2012\end{array}$ & $\begin{array}{l}\text { Edileusa do Socorro Valente Belo - } \\
\text { UFRR } \\
\text { Roseli Araujo Barros - UEG } \\
\text { Tadeu Oliver Gonçalves - UFPA } \\
\text { Elizabeth Cardoso Gerhardt Manfredo } \\
\text { - UFPA }\end{array}$ \\
\hline \multicolumn{3}{|c|}{ EDUCAR EM REVISTA - UFPR } \\
\hline 2014 & $\begin{array}{l}\text { Livros didáticos e formação de professores que ensinam } \\
\text { Matemática nos anos iniciais do Ensino Fundamental }\end{array}$ & $\begin{array}{l}\text { Gláucia Marcondes Vieira - UFMG } \\
\text { Maria Laura Magalhães Gomes - UFMG }\end{array}$ \\
\hline
\end{tabular}

Fonte: Organizado pelas autoras.

\section{APÊNDICE 2}

Quadro 4 - Relação dos trabalhos publicados nos Anais Cipa - 2010-2018

\begin{tabular}{|c|c|c|}
\hline Edição & Autores & Título do trabalho \\
\hline \multirow[t]{5}{*}{ IV CIPA/ 2010} & $\begin{array}{l}\text { ANGELIM, José Aurimar dos } \\
\text { Santos }\end{array}$ & $\begin{array}{l}\text { Meu caminhar pela vida: da infância ao mundo da } \\
\text { Pesquisa em Educação Matemática }\end{array}$ \\
\hline & $\begin{array}{l}\text { ASSIS, Márcia Maria Alves de; } \\
\text { GUTIERRE, Liliane dos Santos }\end{array}$ & $\begin{array}{l}\text { Memória (auto)biográfica sobre o ensino de } \\
\text { Matemática de monitoras da experiência das } \\
\text { escolas radiofônicas do RN }\end{array}$ \\
\hline & $\begin{array}{l}\text { BARROS, Roseli Araújo; } \\
\text { GONÇALVES, Tadeu Oliver }\end{array}$ & $\begin{array}{l}\text { Narrativas docentes: a trajetória de quatro } \\
\text { professoras de Matemática como docentes no } \\
\text { ensino fundamental e médio }\end{array}$ \\
\hline & $\begin{array}{l}\text { CHAQUIAM, Miguel; MENDES, Iran } \\
\text { Abreu }\end{array}$ & A Face acadêmica de Guilherme de La Penha \\
\hline & FILHO, José P. Peixoto & $\begin{array}{l}\text { O ensino da Matemática e o fracasso dos alunos: } \\
\text { Insatisfações e conflitos nas histórias orais da vida } \\
\text { de professores do ensino fundamental }\end{array}$ \\
\hline
\end{tabular}




\begin{tabular}{|c|c|c|}
\hline \multirow[t]{12}{*}{ IV CIPA/ 2010} & GUARNICA, Vicente Marafioti & $\begin{array}{l}\text { Para um mapeamento da formação de professores } \\
\text { de Matemática no Brasil: considerações sobre a } \\
\text { História Oral como método qualitativo de pesquisa } \\
\text { que envolve oralidade, memória, temporalidade e } \\
\text { narrativas }\end{array}$ \\
\hline & JABLONSKI, Annanda Diléia & $\begin{array}{l}\text { Expressões dos imaginários das crianças em aulas } \\
\text { onde a Matemática mistura-se com a literatura } \\
\text { infantil }\end{array}$ \\
\hline & $\begin{array}{l}\text { LAMONATO, Maiza; PASSOS, } \\
\text { Cármen Lúcia Brancaglion }\end{array}$ & $\begin{array}{l}\text { Narrativas de formação: aprendizagens docentes a } \\
\text { partir da exploração-investigação matemática em } \\
\text { geometria }\end{array}$ \\
\hline & $\begin{array}{l}\text { MEGID, Maria Auxiliadora Bueno } \\
\text { Andrade }\end{array}$ & Escrever sobre Matemática, que história é essa? \\
\hline & $\begin{array}{l}\text { MELO, José Ronaldo; FIORENTINI, } \\
\text { Dario }\end{array}$ & $\begin{array}{l}\text { Histórias de vida e práticas de formação docente } \\
\text { de formadores de professores de Matemática }\end{array}$ \\
\hline & NACARATO, Adair Mendes & $\begin{array}{l}\text { Narrativas (auto)biográficas: artes de conhecer } \\
\text { como professores de Matemática se constituem } \\
\text { profissionalmente }\end{array}$ \\
\hline & $\begin{array}{l}\text { NAKAYAMA, Bárbara C. M. } \\
\text { Sicardini; TINTI, Douglas da } \\
\text { Silva; JANUÁRIO, Gilberto. }\end{array}$ & $\begin{array}{l}\text { Percursos de formação e (auto)formação em } \\
\text { Educação Matemática: tendências, desafios e } \\
\text { perspectivas }\end{array}$ \\
\hline & $\begin{array}{l}\text { PASSOS, Carmem Lúcia } \\
\text { Brancaglion }\end{array}$ & $\begin{array}{l}\text { Narrativas de professores e licenciandos de } \\
\text { Matemática participantes em grupo de estudos }\end{array}$ \\
\hline & PESSOA, Wilton Rabelo & $\begin{array}{l}\text { Pesquisa (auto)biográfica em Educação em Ciências } \\
\text { e Matemática }\end{array}$ \\
\hline & RIPARDO, Ronaldo Barros & $\begin{array}{l}\text { Por entre as letras e a Matemática: história de vida } \\
\text { de um educador matemático letrado }\end{array}$ \\
\hline & SILVA, Vicente Eudes Veras da & $\begin{array}{l}\text { A função da análise retórica na (trans) formação da } \\
\text { pessoa- professor na sala de aula de Matemática }\end{array}$ \\
\hline & $\begin{array}{l}\text { STAVIS, Jaqueline Cristiane; } \\
\text { NACARATO, Adair Mendes }\end{array}$ & $\begin{array}{l}\text { Iniciação à Matemática: o percurso histórico do } \\
\text { material e sua contribuição para a prática docente } \\
\text { na voz do seu idealizador }\end{array}$ \\
\hline \multirow[t]{5}{*}{ V CIPA/ 2012} & CAPORALE, Silvia Maria Medeiros & $\begin{array}{l}\text { Memorial de formação de uma futura professora } \\
\text { de Matemática: composição de diversas vozes }\end{array}$ \\
\hline & $\begin{array}{l}\text { COSTA, Joacir Marques da; } \\
\text { CARDÔZO, Lisliane dos Santos; } \\
\text { HENZ, Celso Ilgo }\end{array}$ & $\begin{array}{l}\text { Peregrinos de si: avaliação em narrativas de } \\
\text { professores de Matemática. }\end{array}$ \\
\hline & $\begin{array}{l}\text { FILHO, José Pereira Peixoto; } \\
\text { SOUZA, Geraldo de }\end{array}$ & $\begin{array}{l}\text { A construção do conhecimento matemático e } \\
\text { trajetórias de vida: diálogo entre as perspectivas } \\
\text { filosóficas e pedagógicas de Paulo Freire com o } \\
\text { pensamento pedagógico de Vigotski e Bakhtin }\end{array}$ \\
\hline & $\begin{array}{l}\text { GOMES, Adriana Aparecida } \\
\text { Molina. }\end{array}$ & $\begin{array}{l}\text { Os sentidos e o sentir na educação de jovens e } \\
\text { adultos (EJA). }\end{array}$ \\
\hline & $\begin{array}{l}\text { GONÇALVES, Terezinha Valim } \\
\text { Oliver }\end{array}$ & $\begin{array}{l}\text { Ideias, memórias e trajetórias de professores } \\
\text { formadores de professores de Ciências e } \\
\text { Matemática: necessidades e experiências } \\
\text { formativas }\end{array}$ \\
\hline
\end{tabular}




\begin{tabular}{|c|c|c|}
\hline \multirow[t]{6}{*}{ V CIPA/ 2012} & $\begin{array}{l}\text { MANFREDO, Elizabeth Cardoso } \\
\text { Gerhardt; GONÇALVES, Tadeu } \\
\text { Oliver }\end{array}$ & $\begin{array}{l}\text { Gênese da docência em professores formadores } \\
\text { em Matemática. }\end{array}$ \\
\hline & $\begin{array}{l}\text { MARTINS, Rosana Maria; ROCHA, } \\
\text { Simone Albuquerque da }\end{array}$ & $\begin{array}{l}\text { Intersubjetividade na constituição da identidade } \\
\text { docente: os licenciandos de Matemática e as trilhas } \\
\text { narradas nos memoriais de formação }\end{array}$ \\
\hline & NACARATO, Adair Mendes & $\begin{array}{l}\text { Trajetórias de professores de Matemática: } \\
\text { resistências e desafios profissionais no início de } \\
\text { carreira }\end{array}$ \\
\hline & RIOS, Claudene Ferreira Mendes & $\begin{array}{l}\text { O pedagogo e a compreensão de si enquanto } \\
\text { professor de Matemática nos anos iniciais da } \\
\text { educação básica: desafios e perspectivas }\end{array}$ \\
\hline & $\begin{array}{l}\text { PRANKE, Amanda; FRISON, } \\
\text { Lourdes Maria Bragagnolo }\end{array}$ & $\begin{array}{l}\text { Narrativas autobiográficas e autorregulação da } \\
\text { aprendizagem: contribuições para a formação de } \\
\text { professores de Matemática }\end{array}$ \\
\hline & $\begin{array}{l}\text { ZAQUEU, Ana Cláudia Molina; } \\
\text { SILVA, Heloisa da }\end{array}$ & $\begin{array}{l}\text { Utilizando narrativas para a compreensão da ação } \\
\text { de programas de formação de professores }\end{array}$ \\
\hline \multirow[t]{13}{*}{ VI CIPA/ 2014} & $\begin{array}{l}\text { ANGELIM, José Aurimar dos } \\
\text { Santos; MATOS; Monica } \\
\text { Gonçalves de }\end{array}$ & $\begin{array}{l}\text { A importância da pesquisa narrativa na Proposição } \\
\text { investigativa de doutorandos em educação } \\
\text { Matemática }\end{array}$ \\
\hline & BARBATO, Christiane Novo & $\begin{array}{l}\text { A constituição da identidade docente de uma } \\
\text { formadora de professores de Matemática: entre } \\
\text { idealizações, mitos e (des)construções }\end{array}$ \\
\hline & BARROS, Roseli Araujo & $\begin{array}{l}\text { Narrativas de professoras de Matemática sobre a } \\
\text { prática docente }\end{array}$ \\
\hline & CAPORALE, Silvia Maria Medeiros & $\begin{array}{l}\text { A escrita do memorial como prática de (auto) } \\
\text { formação de futuros professores de Matemática }\end{array}$ \\
\hline & COSTA; Francisca Vandilma & $\begin{array}{l}\text { Matemática Grega e narrativa em formação } \\
\text { docente }\end{array}$ \\
\hline & $\begin{array}{l}\text { D'AMBROSIO, Beatriz Silva; } \\
\text { LOPES, Celi Espasandin }\end{array}$ & $\begin{array}{l}\text { Modos de uma professora de Matemática narrar as } \\
\text { suas Ações de insubordinação criativa }\end{array}$ \\
\hline & FLUGGE, Flávia Cristina Gomes & $\begin{array}{l}\text { As narrativas como recurso pedagógico na } \\
\text { formação inicial do professor dos anos iniciais em } \\
\text { Matemática }\end{array}$ \\
\hline & LOBATO, Maria José Silva & O bicho papão: a raiz do problema em Matemática \\
\hline & LOPES; João Maria da Silva & \\
\hline & MOURA, Jónata Ferreira de & $\begin{array}{l}\text { Narrativas de vida de professores da educação } \\
\text { infantil: as marcas da Matemática escola e suas } \\
\text { práticas ao ensinarem Matemática }\end{array}$ \\
\hline & NACARATO, Adair Mendes & $\begin{array}{l}\text { Narrativas de vida de professores que ensinam } \\
\text { Matemática: questões metodológicas }\end{array}$ \\
\hline & $\begin{array}{l}\text { PEREIRA, Carlos André Bogéa; } \\
\text { SOARES, Waléria de Jesus } \\
\text { Barbosa Soares }\end{array}$ & $\begin{array}{l}\text { João Antonio Coqueiro: vestígios da história de vida } \\
\text { na constituição de um matemático }\end{array}$ \\
\hline & RIOS, Claudene Ferreira Mendes & $\begin{array}{l}\text { (Auto)biografia e o ensino e a aprendizagem de } \\
\text { Matemática: outras possibilidades para a formação } \\
\text { do pedagogo }\end{array}$ \\
\hline
\end{tabular}




\begin{tabular}{|c|c|c|}
\hline \multirow[t]{7}{*}{ VI CIPA/ 2014} & $\begin{array}{l}\text { ROSA; Fernanda Malinosky } \\
\text { Coelho da; BARALDI, Ivete } \\
\text { Maria }\end{array}$ & $\begin{array}{l}\text { Narrativas (auto)biográficas em um blog: a } \\
\text { investigação da formação de professores (de } \\
\text { Matemática) para a Educação Inclusiva }\end{array}$ \\
\hline & $\begin{array}{l}\text { ROSA, Fernanda Malinosky } \\
\text { Coelho da; } \\
\text { ZAQUEU, Ana claudia Molina }\end{array}$ & $\begin{array}{l}\text { Histórias de vida: a escrita de professores } \\
\text { De Matemática em duas pesquisas sobre formação }\end{array}$ \\
\hline & SILVA, Heloisa da & $\begin{array}{l}\text { Por que o sinal de mais embaixo do zero? } \\
\text { Narrativas no estudo de estratégias de cálculo num } \\
\text { curso de Licenciatura em Matemática }\end{array}$ \\
\hline & $\begin{array}{l}\text { SOUZA, Ana Paula Gestoso } \\
\text { de; PASSOS, Cármen Lúcia } \\
\text { Brancaglion }\end{array}$ & $\begin{array}{l}\text { Concepções de estudantes de pedagogia e de } \\
\text { professores dos anos iniciais: narrativas de } \\
\text { formação, ensino de Matemática, tecnologia digital }\end{array}$ \\
\hline & TIZZO, Vinícius Sanches & $\begin{array}{l}\text { Sobre potencialidades das narrativas na (e para a) } \\
\text { formação de professores de Matemática }\end{array}$ \\
\hline & $\begin{array}{l}\text { ZAQUEU, Ana Claudia Molina; } \\
\text { SILVA, Heloisa da }\end{array}$ & $\begin{array}{l}\text { Narrativas (auto)biográficas e história oral: } \\
\text { possibilidades e limitações em pesquisas da } \\
\text { Educação Matemática }\end{array}$ \\
\hline & $\begin{array}{l}\text { ALBUQUERQUE, Jacirene } \\
\text { Vasconcelos de; ALVES, } \\
\text { Lourimara Farias Barros; } \\
\text { GONÇALVES, Terezinha Valim } \\
\text { Oliver }\end{array}$ & $\begin{array}{l}\text { Formação e docência de professores de Ciências e } \\
\text { Matemática: narrativas do passado para práticas } \\
\text { do presente e projeções futuras }\end{array}$ \\
\hline \multirow[t]{9}{*}{ VII CIPA/ 2016} & $\begin{array}{l}\text { ALVES; Lourimara Farias Barros; } \\
\text { GONÇALVES, Terezinha Valim } \\
\text { Oliver; ALBUQUERQUE, Jacirene } \\
\text { Vasconcelos de }\end{array}$ & $\begin{array}{l}\text { Formação e docência de professores de Ciências e } \\
\text { Matemática: narrativas do passado para práticas } \\
\text { do presente e projeções futuras }\end{array}$ \\
\hline & $\begin{array}{l}\text { ANGELIM, José Aurimar dos } \\
\text { Santos; BELO, VALENTE, Edileusa } \\
\text { do Socorro; MATOS, Monica } \\
\text { Gonçalves de }\end{array}$ & $\begin{array}{l}\text { Tadeu Oliver Gonçalves: traços impressos na } \\
\text { formação de professores-pesquisadores de } \\
\text { Matemática }\end{array}$ \\
\hline & ARAÚJO, Maria José Lopes de & $\begin{array}{l}\text { Relembrar é refazer-se: em busca de um objeto de } \\
\text { pesquisa }\end{array}$ \\
\hline & $\begin{array}{l}\text { BARROS, Roseli Araujo; MATOS, } \\
\text { Monica Gonçalves de }\end{array}$ & $\begin{array}{l}\text { Memórias da escola: a figura do bom } \\
\text { professor nos relatos narrativos de licenciandos } \\
\text { em Matemática }\end{array}$ \\
\hline & $\begin{array}{l}\text { BELO, Edileusa do Socorro } \\
\text { Valente; BARROS, Roseli Araujo }\end{array}$ & $\begin{array}{l}\text { Epistemologia qualitativa e pesquisa narrativa: } \\
\text { perspectivas (auto)biográficas para a formação de } \\
\text { professores de Matemática }\end{array}$ \\
\hline & BERNARDO, Renata & $\begin{array}{l}\text { Jovens universitários, suas memórias escolares e as } \\
\text { trajetórias de formação }\end{array}$ \\
\hline & $\begin{array}{l}\text { BOLOGNANI, Marjorie Samira } \\
\text { Ferreira }\end{array}$ & $\begin{array}{l}\text { Narrativas de si e trajetórias } \\
\text { de formação no grupo de discussão-reflexão: a } \\
\text { professora Alexandra }\end{array}$ \\
\hline & CAPORALE, Silvia Maria Medeiros & $\begin{array}{l}\text { Escrever e compartilhar histórias de vida: uma } \\
\text { prática de (auto)formação de futuros professores } \\
\text { de Matemática }\end{array}$ \\
\hline & FERREIRA, Maycon Douglas & $\begin{array}{l}\text { Narrativas (auto)biográficas: reflexões sobre a } \\
\text { formaçãao inicial de professores de Matemática no } \\
\text { âmbito do PIBID }\end{array}$ \\
\hline
\end{tabular}




\begin{tabular}{|c|c|c|}
\hline \multirow[t]{13}{*}{ VII CIPA/ 2016} & KLEINE, Martha Regina Egéa & $\begin{array}{l}\text { Formação do professor em serviço: desafios e } \\
\text { dificuldades }\end{array}$ \\
\hline & LUVISON, Cidinéia da Costa & $\begin{array}{l}\text { Experiências narrativas com alunos do } 3 \text { o ano do } \\
\text { Ensino Fundamental: um processo de pertença }\end{array}$ \\
\hline & MONTEZUMA, Luci Fatima & $\begin{array}{l}\text { Narrativas de professoras que ensinam Matemática } \\
\text { nos anos iniciais - os desafios da profissão na } \\
\text { educação } \\
\text { Pública estadual paulista }\end{array}$ \\
\hline & MOURA, Jónata Ferreira de & $\begin{array}{l}\text { Trajetória de formação inicial de professoras } \\
\text { da Educação Infantil: a Matemática escolar em } \\
\text { evidência }\end{array}$ \\
\hline & $\begin{array}{l}\text { OLIVEIRA, Iara Leticia Leite de; } \\
\text { CARVALHO, Rosana Areal de }\end{array}$ & Escrita de si e formação docente \\
\hline & OLIVEIRA, Thais de & $\begin{array}{l}\text { Aprendizagem e constituição profissional de uma } \\
\text { professora de Matemática: um estudo de si }\end{array}$ \\
\hline & $\begin{array}{l}\text { PASSOS, Cármen Lúcia } \\
\text { Brancaglion; NACARATO, } \\
\text { Adair Mendes; SILVA, Heloisa da }\end{array}$ & Narrativas em Educação Matemática \\
\hline & $\begin{array}{l}\text { PEREIRA, Carlos André Bogéa; } \\
\text { RODRIGUES, Margarida }\end{array}$ & $\begin{array}{l}\text { Narrativas de formadoras de professores/as que } \\
\text { ensinam Matemática em Portugal }\end{array}$ \\
\hline & $\begin{array}{l}\text { REINATO, Rosicler Aparecida de } \\
\text { Oliveira }\end{array}$ & $\begin{array}{l}\text { Narrativas de estudantes do ensino técnico } \\
\text { profissional de nível médio do IFSULDEMINAS } \\
\text { Campus Machado: um olhar sobre o ensino e o } \\
\text { currículo de Matemática }\end{array}$ \\
\hline & RIOS, Claudene Ferreira Mendes & $\begin{array}{l}\text { O ensino de Matemática no estágio supervisionado } \\
\text { do curso de Pedagogia: narrativas e reflexões }\end{array}$ \\
\hline & $\begin{array}{l}\text { SILVA, Américo Junior Nunes da; } \\
\text { PASSOS, Cármen Lucia } \\
\text { Brancaglion }\end{array}$ & $\begin{array}{l}\text { O diário reflexivo do professor que ensinará } \\
\text { Matemática nos anos iniciais: o que revelam sobre } \\
\text { a formação inicial e sua futura prática profissional }\end{array}$ \\
\hline & $\begin{array}{l}\text { SILVA; Fabio Colins da; JÚNIOR } \\
\text { Arthur Gonçalves Machado }\end{array}$ & $\begin{array}{l}\text { "Na minha época, a alfabetização Matemática era } \\
\text { assim..." }\end{array}$ \\
\hline & $\begin{array}{l}\text { SOARES, Waléria de Jesus } \\
\text { Barbosa }\end{array}$ & $\begin{array}{l}\text { José Augusto Corrêa: um literato entre o ensino de } \\
\text { Língua Portuguesa e o ensino de Matemática }\end{array}$ \\
\hline \multirow[t]{5}{*}{ VIII CIPA/ 2018} & $\begin{array}{l}\text { ABREU, Maria das Graças dos } \\
\text { Santos; MEGID, Maria Auxiliadora } \\
\text { Bueno Andrade }\end{array}$ & $\begin{array}{l}\text { Os programas de formação na licenciatura em } \\
\text { Matemática: perspectivas e contribuições }\end{array}$ \\
\hline & $\begin{array}{l}\text { ALMEIDA, Talita Carvalho Silva } \\
\text { de; CABRAL, Clara Alice F }\end{array}$ & $\begin{array}{l}\text { Um mergulho nas memórias: reflexões } \\
\text { sobre a prática em aulas de Matemática }\end{array}$ \\
\hline & $\begin{array}{l}\text { ALVES, Lourimara Farias } \\
\text { Barros; ALBUQUERQUE Jacirene } \\
\text { Vasconcelos de; ARAGÃO, Rosália } \\
\text { Maria Ribeiro de }\end{array}$ & $\begin{array}{l}\text { Narrativas auto(biográficas) de formação doutoral } \\
\text { de professores de ciências e Matemática }\end{array}$ \\
\hline & $\begin{array}{l}\text { ARAÚJO, Maria José Lopes de; } \\
\text { FRAIHA-MARTINS, France }\end{array}$ & $\begin{array}{l}\text { Práticas docentes em Matemática: repercuções das } \\
\text { experiências de vida e formação }\end{array}$ \\
\hline & BARBOSA, Josane Geralda & $\begin{array}{l}\text { Biografias de matemáticos ou professores de } \\
\text { Matemática }\end{array}$ \\
\hline
\end{tabular}


VIII CIPA/ 2018
CABRAL, Clara Alice F; ALMEIDA,

Talita Carvalho Silva de; DIAS, Josete Leal

COURA, Flávia Cristina

Figueiredo; PASSOS, Carmen

Lucia Brancaglion

CUSTÓDIO, Iris Aparecida; CAPORALE, Silvia Maria Medeiros

EVANGELISTA, Maria Tereza
Fernandino

LINS, Ariane Cristine Lima; PEDROSA, Eliane Maria Pinto

LUCAS, Gilmar Afonso de ROSITO, Margaréte May Berkenbrock

MORAES, César Augusto do Prado; AZEVEDO, Adriana Barroso de

MOREIRA, Katia Gabriela
Composições escritas em Matemática: análise em tarefas de aprendizagem e de avaliação

A pesquisa narrativa como forma de compreender experiências de desenvolvimento profissional de formadores de professores de Matemática que são investigadores da docência

Tecendo (re)significações para a escrita do memorial como prática formativa

Experiências e trajetórias de formação de ex-alunos do COLUNI: sob o prisma da Matemática

Narrativas docentes sobre as contribuições de Paulo Freire na formação de professores de Matemática

Narrativa autobiográfica do processo de formação: fragmentos da trajetória de um professor de Matemática

Reconfiguração dos significados dos adolescentes sobre o ensino de Matemática vivenciado com o uso das tecnologias digitais

Narrativa de aula de Matemática de uma professora do $1^{\circ}$ ano do Ensino Fundamental: uma reflexão na/da própria prática

OLIVEIRA, Iara Leticia Leite de; SILVA, Fernanda Aparecida Oliveira Rodrigues

Trajetórias formativas e escrita de si: um olhar para as narrativas de professores de Matemática

Na transversalidade da Matemática: a escuta

PAIXÃO, Cláudia Melo da; SAMPAIO, Tereza Verena Melo da Paixão compreensiva das narrativas como um dispositivo didático para compreender as limitações do sujeito no processo de ensino-aprendizagem

Constituindo-nos pesquisadores narrativos em Educação em Ciências e Matemáticas em ambientes stricto sensu Mauro Guterres

RIBEIRO, Caroline de Paula; BOTELHO, Luiza Palmira Freitas; MIRANDA, Ana Paula Santiago; CARNEIRO, Reginaldo Fernando

Narrativas nas pesquisas em formação de professores na Educação Matemática: um estudo teórico

Narrativas como dispositivo de formação para RIOS, Claudene Ferreira Mendes pedagogos: reflexões sobre o aprender e o ensinar Matemática

Formação continuada de professores:

SANTOS, Camila Amorim Moura dos; SILVA, Enoilma Simões Paixão Correia narrativas de uma professora-cursista do projeto gestar na escola sobre o processo de ensino e aprendizagem da Matemática com atividades de leitura, escrita e resolução de problemas para estudantes do 6o ano

SANTOS, Patrícia Corrêa; LOPES, Celi Espasandin
As narrativas autobiográficas de Educadores matemáticos: desvelando ações de insubordinação criativa num processo de autoformação 


\begin{tabular}{|l|l|l|}
\cline { 2 - 3 } VIII CIPA/ 2018 & $\begin{array}{l}\text { SCARLASSARI, Nathalia Tornsiello } \\
\text { LOPES; Celi Espasandin }\end{array}$ & $\begin{array}{l}\text { O trajeto profissional narrado por professores } \\
\text { inseridos em um contexto de formação continuada }\end{array}$ \\
\cline { 2 - 3 } & $\begin{array}{l}\text { SILVA, Américo Junior Nunes da; } \\
\text { PASSOS, Carmen Lucia } \\
\text { Brancaglion }\end{array}$ & $\begin{array}{l}\text { Querido diário: o que revelam as narrativas sobre } \\
\text { ludicidade, formação e futura prática do professor } \\
\text { que ensina(rá) Matemática nos anos iniciais }\end{array}$ \\
\cline { 2 - 3 } & $\begin{array}{l}\text { SILVA, Eliel Moraes da; } \\
\text { FAGUNDES, Isabelle Pinheiro }\end{array}$ & $\begin{array}{l}\text { Ensino da Matemática em pesquisas com o método } \\
\text { autobiográfico: um levantamento bibliográfico }\end{array}$ \\
\hline $\begin{array}{l}\text { SILVA, Marinéia dos Santos; } \\
\text { SILVA, Heloisa da }\end{array}$ & $\begin{array}{l}\text { Alguns movimentos (de entrada e circulação) das } \\
\text { narrativas a partir dos grupos de pesquisa na } \\
\text { Educação Matemática }\end{array}$ \\
\hline TOILLIER, Jean Sebastian & $\begin{array}{l}\text { História oral e biografia: interlocuções possíveis em } \\
\text { Educação Matemática }\end{array}$ \\
\hline
\end{tabular}

Fonte: Organizado pelas autoras. 